\title{
Effect of age at vaccination on the measles vaccine effectiveness and immunogenicity: systematic review and meta-analysis
}

\author{
Sara Carazo ${ }^{1}$, Marie-Noëlle Billard ${ }^{2}$, Amélie Boutin ${ }^{2}$ and Gaston De Serres ${ }^{1,2,3^{*}}$ (D)
}

\begin{abstract}
Background: The objectives of this review were to evaluate the effect of age at administration of the first dose of a measles-containing vaccine (MCV1) on protection against measles and on antibody response after one- and twodose measles vaccinations.

Methods: We conducted a systematic review of the PubMed/MEDLINE, Embase, Web of Science and Cochrane databases (1964-2017) to identify observational studies estimating vaccine effectiveness and/or measles attack rates by age at first vaccination as well as experimental studies comparing seroconversion by age at first vaccination. Random effect models were used to pool measles risk ratios (RR), measles odds ratios (OR) and seroconversion RR of MCV1 administered at $<9,9-11$ or $\geq 15$ months compared with 12 or 12-14 months of age.

Results: We included 41 and 67 studies in the measles protection and immunogenicity analyses. Older age at MCV1, from 6 to $\geq 15$ months, improved antibody response and measles protection among one-dose recipients. Pooled measles RR ranged from 3.56 (95\%Cl: 1.28, 9.88) for MCV1 at < 9 months to $0.48(95 \% \mathrm{Cl}: 0.36,0.63)$ for MCV1 at $\geq 15$ months, both compared to 12-14 months. Pooled seroconversion RR ranged from 0.93 (95\%Cl: 0.90, 0.96) for MCV1 at 9-11 months to 1.03 (95\%Cl: 1.00, 1.06) for MCV1 at $\geq 15$ months, both compared to 12 months. After a second dose, serological studies reported high seropositivity regardless of age at administration of MCV1 while epidemiological data based on few studies suggested lower protection with earlier age at MCV1.

Conclusions: Earlier age at MCV1 decreases measles protection and immunogenicity after one dose and might still have an impact on vaccine failures after two doses of measles vaccine. While two-dose vaccination coverage is most critical to interrupt measles transmission, older age at first vaccination may be necessary to keep the high level of population immunity needed to maintain it.
\end{abstract}

Keywords: Measles vaccine, Age, Immunogenicity, Effectiveness

\section{Background}

The introduction of measles vaccination in the 1960s helped to control this highly contagious disease [1]. Elimination was achieved in the Americas in 2002 and the World Health Organization (WHO) has set the goal of measles elimination [2].

In one-dose programs, vaccine effectiveness (VE) was influenced by age at vaccination [3-5]. The interference

\footnotetext{
*Correspondence: gaston.deserres@inspq.qc.ca

'Department of Social and Preventive Medicine, Laval University, 1050,

Avenue de la Médecine, Quebec, QC G1V 0A6, Canada

${ }^{2} \mathrm{CHU}$ de Québec - Université Laval Research Center, 2400, Avenue

d'Estimauville, Quebec, QC G1E 7G9, Canada

Full list of author information is available at the end of the article
}

of maternal antibodies and the immaturity of the child's immune system were the alleged mechanisms that resulted in a weaker antibody response and poorer protection in younger infants [6-9]. A second dose of MCV (MCV2) was added to compensate for the primary failures observed after the first vaccination, and two-dose schedules have been a key strategy for measles elimination [2]. However, epidemic investigations $[10,11]$ and serological studies [12] have suggested that the effect of age at MCV1 could persist after two doses, with increased vulnerability among children first vaccinated before 15 months.

(C) The Author(s). 2020 Open Access This article is distributed under the terms of the Creative Commons Attribution 4.0 International License (http://creativecommons.org/licenses/by/4.0/), which permits unrestricted use, distribution, and 
The recommended age at first dose is a compromise, balancing the advantage of older immunization with the risk of measles in infants [13]. Depending upon the country, the first dose of measles-containing vaccine (MCV1) is currently administered from 9 to 18 months of age, with vaccination recommended as early as 6 months in specific situations [14-16].

In their systematic review, Uzicanin and Zimmerman [17] reported a VE of 84 to $93 \%$ after one and of $94 \%$ after two doses of vaccine. They presented VE summary point estimates for one dose administered at 9-11 (77\%) or $\geq 12$ months (92\%). A Cochrane review studied the effectiveness and safety of the measles-mumps-rubella vaccine but without accounting for age at vaccination [18]. Finally, a recent review examined immunogenicity and effectiveness of vaccination at $<9$ months [19]. None of them have systematically reviewed the impact of a change in age at MCV1 on the vaccine response. In order to control measles or to maintain measles elimination, public health stakeholders have to decide on best vaccination schedules based on their country's epidemiology, health system characteristics and best evidence on the effect of age at vaccination.

We aimed to evaluate the effect of age at administration of MCV1 on protection against measles and antibody response after one- and two-dose measles vaccinations through a systematic review of observational studies estimating $\mathrm{VE}$ and/or measles attack rates (AR) by age at first vaccination as well as experimental studies comparing seroconversion risk by age at first vaccination.

\section{Methods}

We conducted a systematic review of the literature following the Cochrane Handbook for Systematic Reviews of Interventions [20] methodological recommendations, and we reported our results according to the Preferred Reporting Items for Systematic Reviews and MetaAnalyses (PRISMA) statement [21].

The study protocol is available in Additional file 1.

\section{Eligibility criteria}

Eligibility required evaluation of vaccination with one or two doses of further attenuated live MCV. In each study, the first dose had to be administered at different ages, but all before the age of two years.

Cohort and case-control studies that reported VE and measles AR by age at MCV1 were eligible for the review of measles protection. Studies or participants vaccinated during an outbreak were excluded.

Randomized controlled trials (RCT) and quasiexperimental studies were included in the review of immunogenicity if seroconversion after MCV1 and/or seropositivity after MCV2 were reported by age at first vaccination. As both age and antibody detection were objective measures, quasi-experimental designs were thought to give valuable data on the immunogenicity response to measles vaccine. Studies of killed and high titer vaccines were excluded, as well as those examining aerosol or intradermal administration or targeting populations with special characteristics such as immunosuppressed or malnourished children [22]. When different vaccine strains were administered in one study, results were extracted according to the strains to compare children receiving the same strain at different ages.

\section{Search strategy}

Studies were identified by a systematic search of the PubMed/MEDLINE, Embase, Web of Science and Cochrane databases from 1964, when the first measles vaccine was licensed, to May 2017. Reference lists of selected articles and key published reviews [17-19, 23] were also hand-searched.

The following search terms were included: Measles Vaccine, Measles-Mumps-Rubella Vaccine, Measles/prevention and control, Vaccination, Measles Mumps Rubella Varicella vaccine, MMR, MMRV, Vaccine effectiveness, Efficacy, Epidemic, Outbreak, Treatment failure, Vaccine failure, Antibody, Serologic Tests, Seroconversion, Immunogenicity, Age, Age at vaccination, Age at immunization and Age factor. The search strategy, validated by a professional librarian, was adapted to each database. Search results were limited to human studies. Studies published in English, French, Spanish or Portuguese were included (Additional file 1).

\section{Study selection}

After eliminating duplicates using EndNote version X7.1 (New York City: Thomson Reuters, 2011) and manual completion, two reviewers (SCP and MNB) independently selected the studies based on the criteria described here. Any disagreements were resolved by consensus or consulting a third party (GDS). The main reason for exclusion was recorded during the full-text examination.

\section{Data collection process}

Data extraction forms were developed and tested for each sub-analysis (measles protection or immunogenicity).

A single author (SCP or MNB) abstracted data from the studies, which were checked by a second reviewer (SCP or MNB). Authors of original articles were contacted in the event of missing or inaccurate information. When VE or seroconversion risk was not reported but there were enough data to estimate it by age at vaccination, the calculation was done by the reviewers. 


\section{Data items}

We extracted information on the study's characteristics, population, intervention (vaccine strain, age at vaccination, number of doses, interval between doses and vaccine status ascertainment) and outcome (case definition, seroconversion definition, antibody assay methods, attack rates and seroconversion risk). VE was calculated by comparing measles AR among vaccinated and nonvaccinated or comparing the vaccination status of cases and non-cases during measles epidemics [24, 25]. Measles cases were defined by clinical, epidemiological and/ or serological criteria. Attenuated or non-classical measles cases were included only if confirmed by laboratory [13]. Seroconversion was defined, according to the study, as the presence of measles antibodies in individuals with previously undetectable titers, a fourfold increase in their concentration or both. Seropositivity was defined as an antibody concentration higher than the protective threshold [26]. Antibody assay methods included enzyme immunoassays (ELISA), hemagglutination assays (HAI), plaque reduction neutralization tests (PRN) and complement fixation tests (CF) [27, 28].

\section{Risk of bias of individual studies}

Two reviewers (SCP and MNB) independently evaluated the risk of bias for each outcome. For the assessment of observational studies, a scale was adapted from the NICE public health guidance [29] to evaluate the study's representativeness, selection process, comparability of the groups, vaccination status ascertainment, and outcome definition and completeness [25]. The Cochrane collaboration tool [20] was adapted to evaluate the risk of bias in experimental studies (Additional file 1).

\section{Summary measures and synthesis of results}

To summarize measles protection studies, we reported estimates of VE conferred by MCV1 and MCV2 for each age group, and also presented measles risk ratios (RR) or odds ratios (OR) using the age group containing children aged 12 months as the referent group. Immunogenicity was presented as seroconversion risk after MCV1 and seropositivity risk after MCV2 for each age category, as reported in each study. Age groups with less than 10 participants were combined if not including the 12 months category.

Meta-analyses of cohort or case-control studies were conducted to pool RR or OR of measles by age at first vaccination. Studies were included if reporting measles AR among 12 or 12 to 14-month-old children, the reference category, and one of the following comparison groups: < 9 months, 9 to 11 months, $<12$ months or $\geq 15$ months. These age categories were chosen based on current vaccination policies [14-16].
For the immunological studies the reference age category was 12 months, with the same comparison age groups. RR of seroconversion by age at first vaccination were pooled separately according to the post-MCV1 seroconversion definition (fourfold increase in antibody titer, seropositivity among previously seronegative or both). Overall measures of association were reported only if subgroup differences were not significant. All meta-analyses were performed using random effect models in Review Manager version 5.3 (Copenhagen: The Cochrane Collaboration, 2014). Heterogeneity between studies was evaluated using $\mathrm{I}^{2}$ and considered significant if greater than 50\% [30]. Heterogeneity was explored according to the following a priori identified factors: measles case definitions, WHO regions and year of epidemic for the measles protection analysis; and vaccine strain, antibody assay method and year of the study for the immunogenicity analysis.

\section{Risk of bias across studies}

Publication bias was evaluated for each outcome by visual examination of funnel plots.

\section{Additional analyses}

Pre-specified sensitivity analyses of studies with a low risk of bias and of RCT were conducted when appropriate. Finally, a pooled analysis comparing seroconversion after MCV1 administered at 6 versus 9 months was performed a posteriori, considering that there is a recommendation for vaccination at 6 months in the context of epidemics in countries with high measles mortality [14].

\section{Results}

Study selection

After removing duplicates, we screened 2723 references and 108 studies were included in the review (Fig. 1). Selection agreement was $>90 \%$.

\section{Study characteristics}

Of the 41 studies included in the measles protection analysis, there were 29 retrospective cohort and 12 casecontrol studies (Table 1 and Additional file 2) [3-5, 10, $11,31-67]$. Most were conducted in the Americas $(n=$ $21 ; 51 \%)$, Africa $(n=5 ; 12 \%)$ and Western Pacific $(n=5$; $12 \%)$ regions and $59 \%$ reported school epidemics. Vaccination status was verified by written record in 36 studies (88\%) but only 12 studies (29\%) included solely laboratory confirmed cases or epidemiologically linked cases. Although 29 studies were conducted in large epidemics ( $\geq 100$ cases), only 11 (27\%) reported $>100$ cases with data on vaccination status and age and 2 (5\%) presented less than 10 cases.

Of the 67 trials included in the immunogenicity analysis, 8 were RCT, 25 non-RCT and 34 before-after 


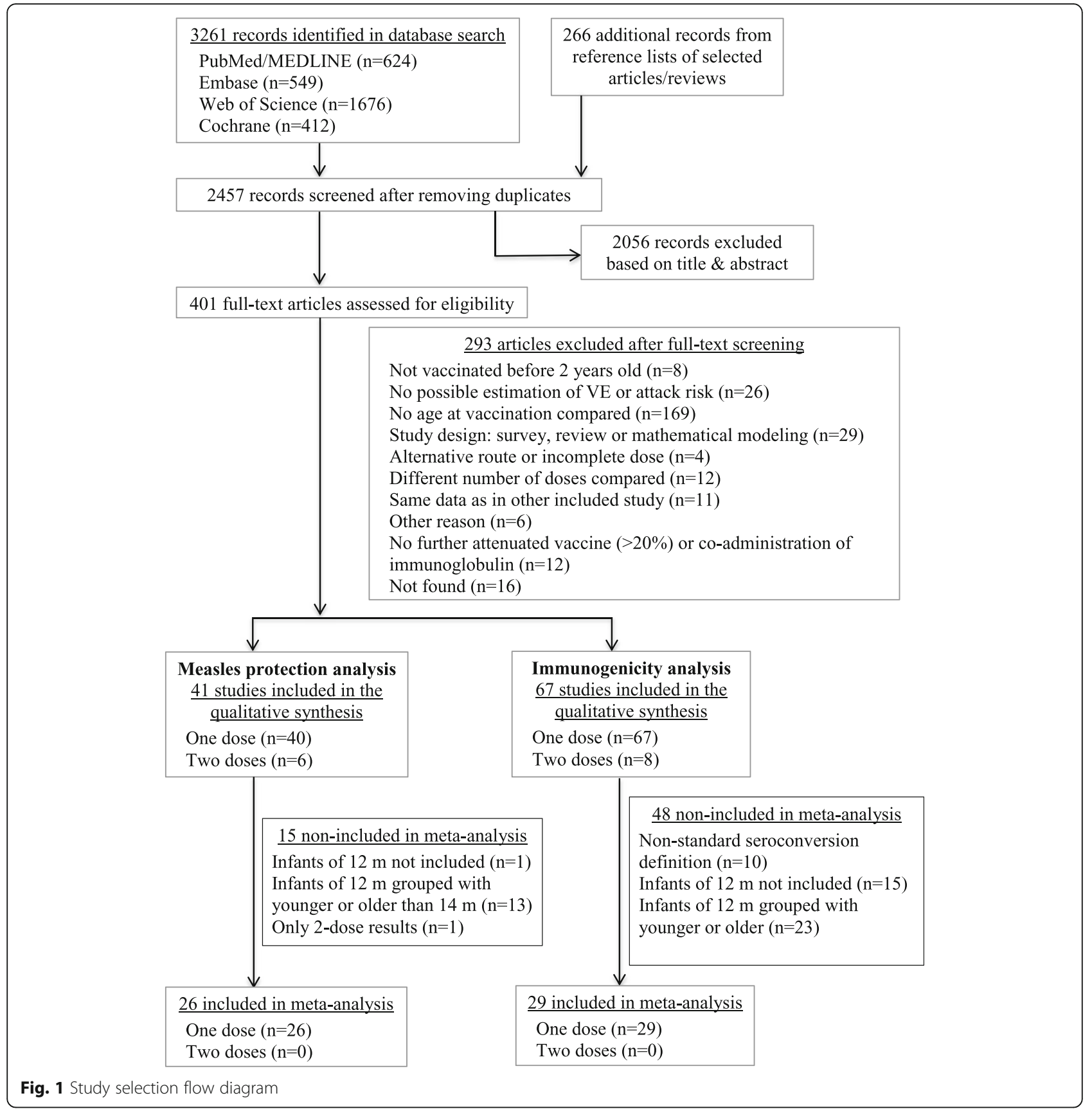

studies (Additional file 2) [6-8, 68-130]. They were conducted in Africa $(n=22 ; 33 \%)$, the Americas $(n=21$; $31 \%)$, Western Pacific $(n=10 ; 15 \%)$ and other regions $(n=14 ; 21 \%)$. Participants were mainly vaccinated with Schwarz $(n=34 ; 42 \%)$ and Moraten strains $(\mathrm{n}=21 ; 30 \%)$ while antibodies were measured using HAI $(n=40$; $60 \%)$, ELISA $(n=12 ; 18 \%)$, PRN $(n=9 ; 13 \%)$ or other assays $(n=6 ; 9 \%)$. Authors defined seroconversion as a fourfold increase in titers $(n=10 ; 15 \%)$, seropositivity among seronegative pre-vaccination $(n=36 ; 54 \%)$, both $(n=11 ; 16 \%)$ or other $(n=10 ; 15 \%)$. Sample size varied from 21 to 1633 participants and 72\% include > 100 vaccinated children.

\section{Risk of bias within studies}

All observational studies were considered to have good representativeness. Only 10 (24\%) had an overall low risk of bias while $14(34 \%)$ and 17 (41\%) presented a moderate or high risk, respectively (Additional file 3). The main biases identified were: selection bias due to potential measles history among non-cases [39, 45, 54]; misclassification due to parents' definition of measles case 


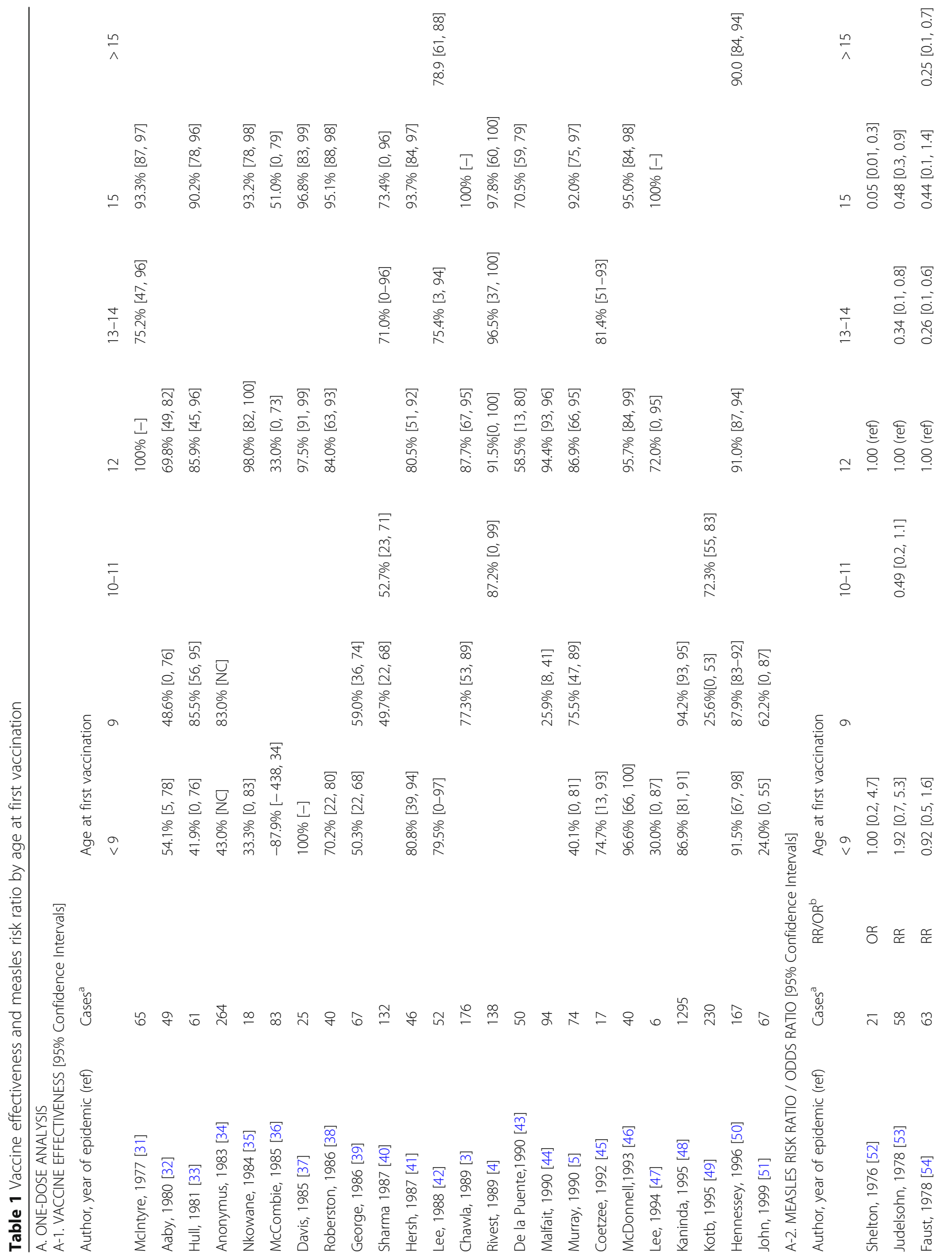




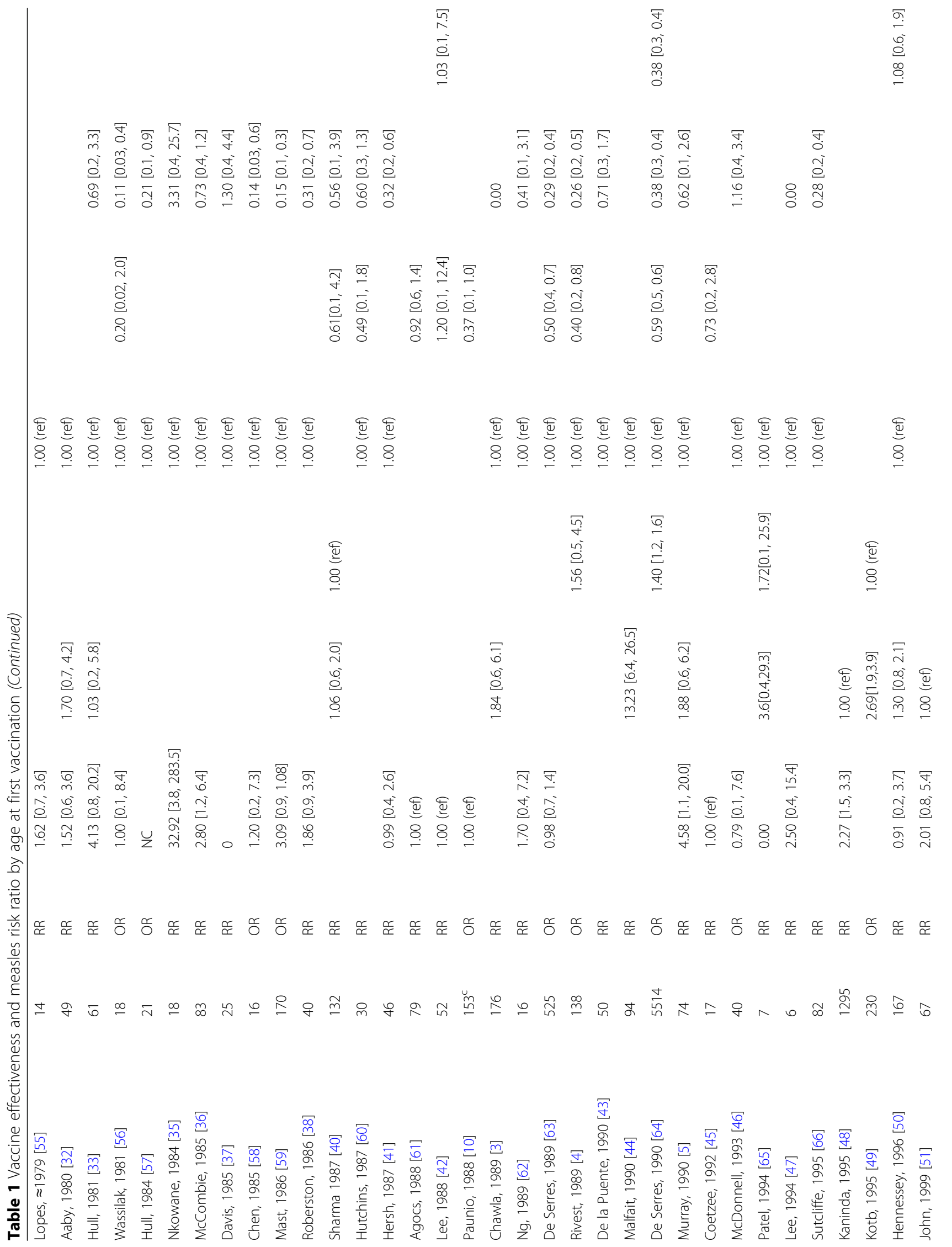




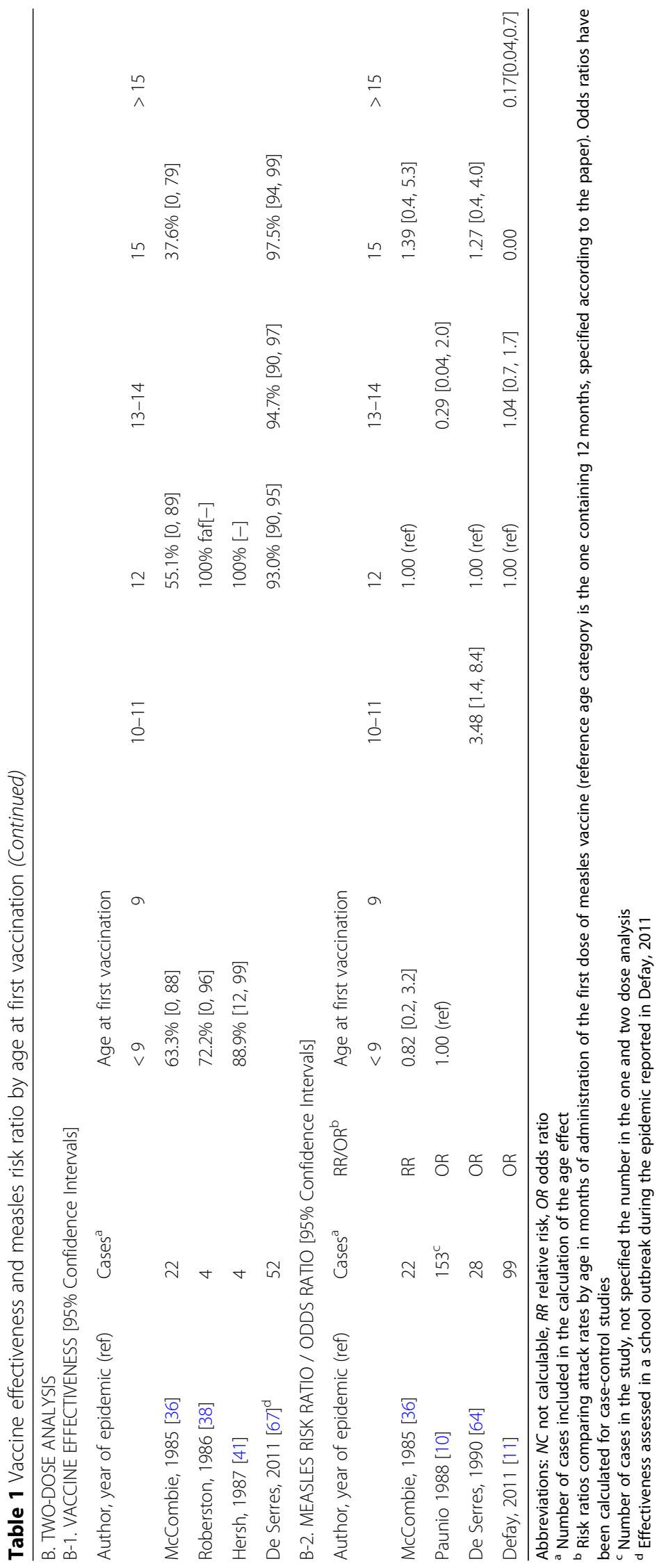


$[3,5,32,33,40,48,49,55]$ and differential verification of vaccination status for cases and non-cases [54]; and confounding bias due to lack of adjustment for time since vaccination $[34,38,47,51,64]$. Among studies included in the meta-analysis, $7(27 \%)$ were at low, 12 $(46 \%)$ at moderate, and $7(27 \%)$ at high risk of bias.

Half of the 8 RCT reporting immunogenicity had a low risk of bias overall $[8,68-70]$ while 4 presented a moderate risk of bias [71-74]. In quasi-experimental studies, 19 (32\%) were considered at low, $26(44 \%)$ at moderate, and $14(24 \%)$ at high risk of bias overall (Additional file 4). Substantial risk of bias was mainly due to potential differential exposure to measles during the study [71, 75-78] and to information bias caused by the use of dried blood spots to measure antibodies [77, 79-91]. Risk of bias of studies included in the metaanalysis was assessed as low in 3 RCT and 6 Non-RCT, moderate in $1 \mathrm{RCT}$ and 8 Non-RCT, and high in 1 Non-RCT.

\section{Measles protection by age at first vaccination}

Of the 41 observational studies included, 24 allowed VE estimates by age at vaccination among one-dose recipients. All 7 studies comparing vaccination at 9-11 months (VE range: $25.9-87.9 \%$ ) versus $\geq 12$ months (VE range: $69.8-94.4 \%)$ found better protection for the latter category (682 cases). Protection was lower in 11 of 13 studies for those vaccinated before (VE range: 33.388.2\%) rather than after 12 months (VE range: 69.896.1\%) (869 cases) and similar in 2 studies (65 cases). VE was lower when the vaccine was administered at 12-14 months (VE range: 58.5-91.5\%) compared to $\geq 15$ months (VE range: $70.5-100 \%$ ) in 8 of 12 studies (651 cases); it was similar in 2 studies and lower at $\geq 15$ months in 2 studies. VE estimations from a school epidemic ranged from $-88 \%$ (MCV1 at $<12$ months) to $51 \%$ (MCV1 at $\geq 15$ months) and were considered biased due to misclassification and lower exposure of unvaccinated children [36] (Table 1A).

Measles RR/OR by age at vaccination could be estimated in 38 studies, 26 of which reported the defined age categories and were included in the meta-analysis. In the pooled analyses of cohort studies, vaccination before 9 months (RR $=3.56,95 \% \mathrm{CI}: 1.281,9.88 ; \mathrm{I}^{2}=0 \%$; 3 studies), at 9 to 11 months ( $\mathrm{RR}=1.04,95 \% \mathrm{CI}: 0.45,2.44$; $\mathrm{I}^{2}=39 \%$; 4 studies $)$ or at $<12$ months $(\mathrm{RR}=1.62,95 \% \mathrm{CI}$ : $1.08,2.43 ; \mathrm{I}^{2}=41 \% ; 13$ studies) were associated with a higher risk of measles compared to vaccination at 12

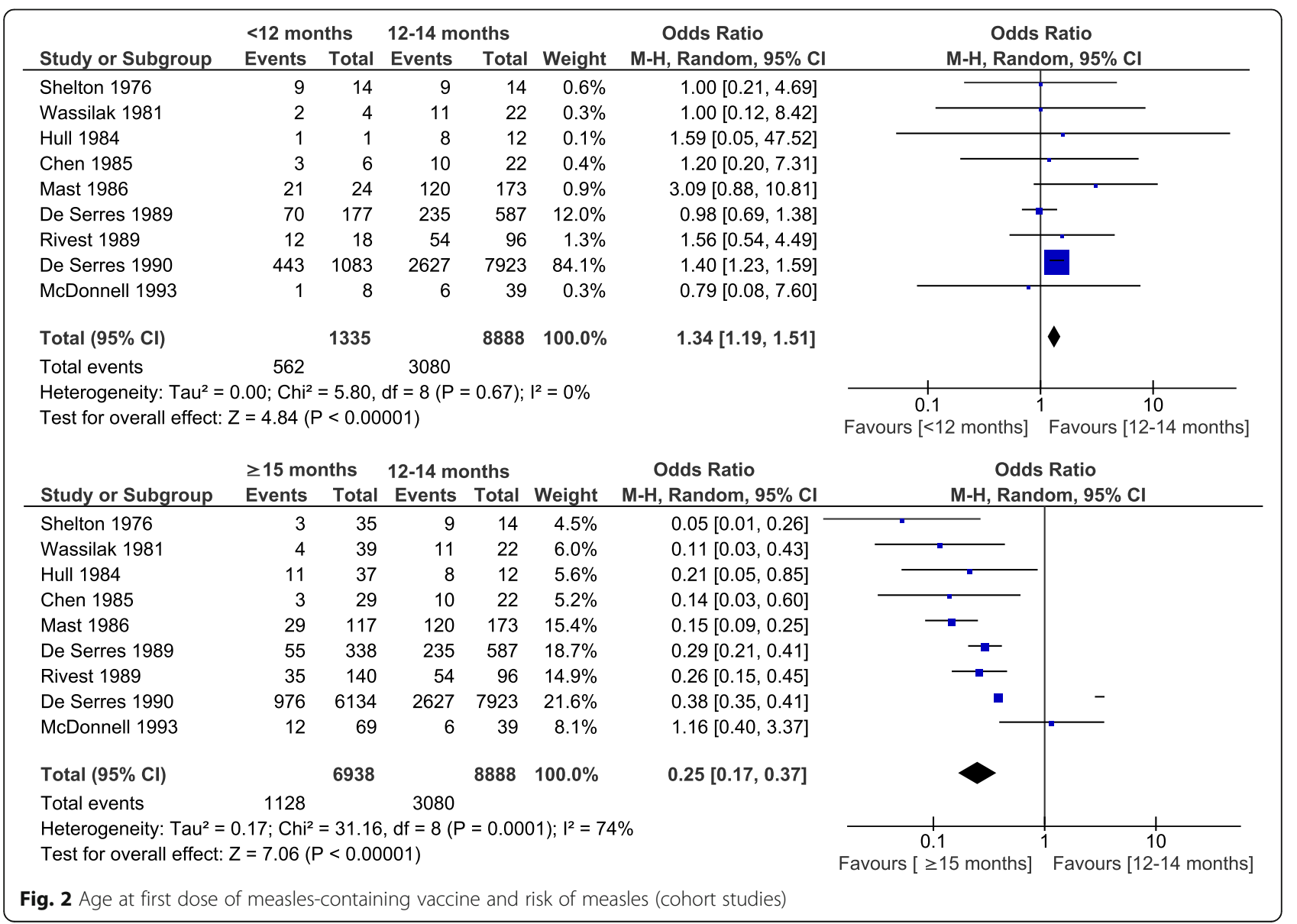


14 months. Conversely, vaccination at $\geq 15$ months was associated with a lower risk than vaccination at 12-14 months $\left(\mathrm{RR}=0.48,95 \% \mathrm{CI}\right.$ : 0.36, 0.63; $\mathrm{I}^{2}=29 \%$; 16 studies) (Fig. 2 and Additional file 5). Similarly, metaanalysis of case-control studies showed a higher risk of measles with early MCV1: < 12 months versus 12-14 months (OR $=1.34,95 \% \mathrm{CI}: 1.19,1.51 ; \mathrm{I}^{2}=0 \%$; 9 studies); and a lower risk for MCV1 at $\geq 15$ months (OR $=0.25$, 95\%CI: 0.17, 0.37; $\mathrm{I}^{2}=74 \%$; 9 studies) (Fig. 3). This last meta-analysis showed significant heterogeneity that was not explained by the predefined factors. The level of evidence of this analysis was considered low to moderate since it was based on observational studies in which a moderate risk of bias persisted but a "dose-response" trend was observed as older age at vaccination (from $<9$ months to $\geq 15$ months) was associated with lower measles risk [131].

Sensitivity analyses with cohort studies at low risk of bias included only 2 of the 18 studies, and only one for each comparison. Case-control studies at low risk of bias (5 out of 9) found a non-significant association comparing vaccination at $<12$ versus 12 months $(\mathrm{OR}=1.03,95 \% \mathrm{CI}: 0.75,1.41)$ and a lower measles risk for vaccination at $\geq 15$ versus 12 months $(\mathrm{OR}=0.31,95 \% \mathrm{CI}: 0.19,0.50)$, similar to that of the main analysis (Additional file 5).

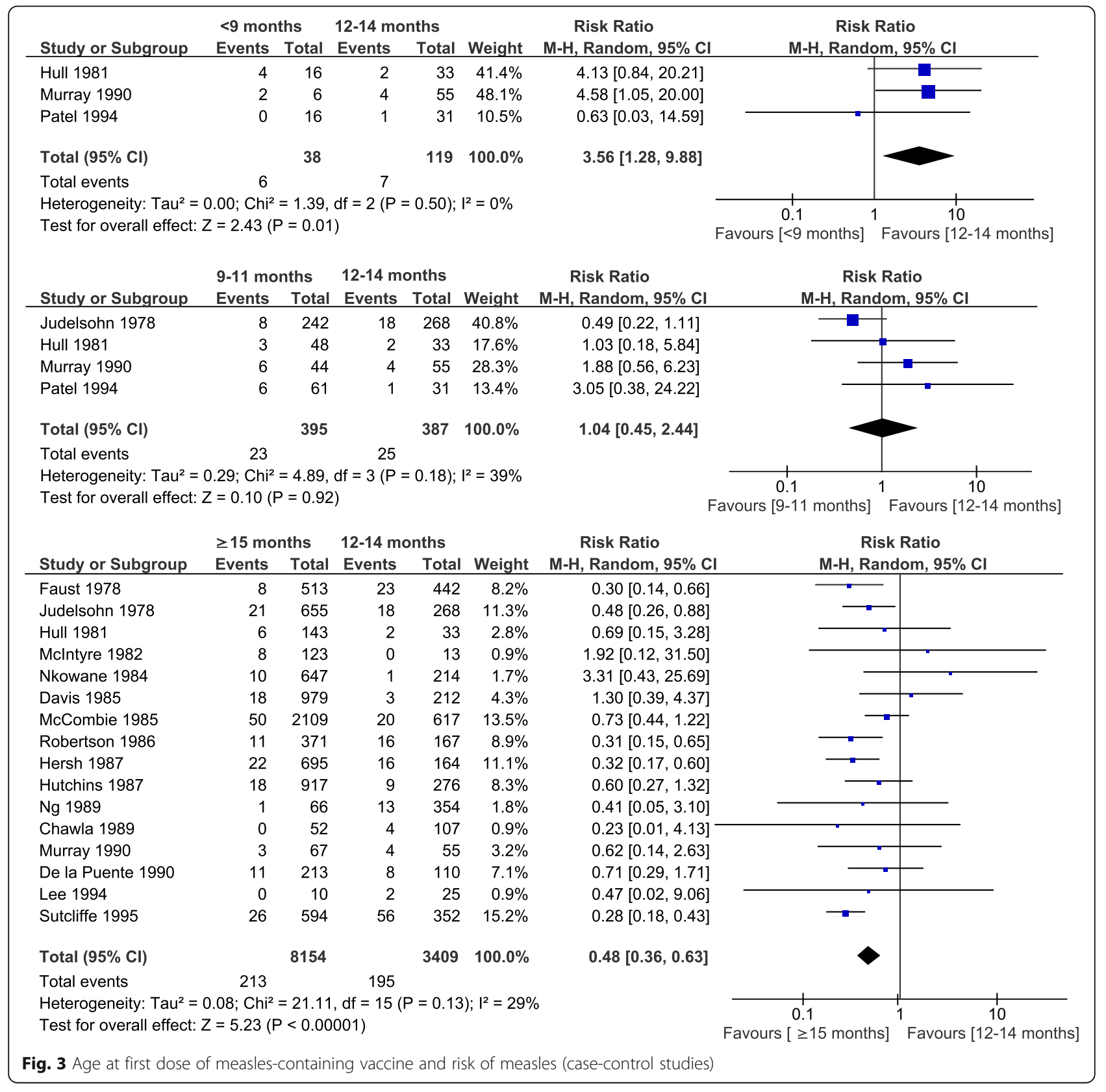


Among two-dose recipients, two studies found lower VE if MCV1 was received at $<12$ months versus at $\geq 12$ months (72 and $89 \%$ versus $100 \%$ ) but based on only one twice-vaccinated case in each study [38, 41]. The largest effectiveness study among two dose recipients (52 cases) reported VE of 93 and $98 \%$ for those first vaccinated at 12 and $\geq 15$ months [67]. Results of 3 case-control studies showed: a lower risk of measles if MCV1 was administered at $\geq 15$ months versus 12 months $\quad(\mathrm{OR}=0.12,95 \% \mathrm{CI}$ : $0.03,0.51$ ) [11]; a non-significant lower risk comparing $\geq 14$ months versus $<14$ months $(\mathrm{OR}=0.29$, 95\%CI: $0.04,2.00$ ) [10]; and a higher risk for those first vaccinated at $10-11$ months $(\mathrm{OR}=3.48,95 \% \mathrm{CI}$ : $1.4,8.4)$ and at $\geq 15$ months $(\mathrm{OR}=1.27,95 \% \mathrm{CI}$ : 0.41 , 3.98) compared to 12-14 months [64] (Table 1B).

\section{Immunogenicity by age at first vaccination}

Of the 67 studies reporting on one-dose immunogenicity, 19 fulfilled the criteria to be included in the metaanalysis (Fig. 1).

Seroconversion was lower in infants with MCV1 $<9$ months than in children vaccinated at 12 months, with RRs of $0.74,0.65$ and 0.99 according to the definition of seroconversion (fourfold increase in titers (4 studies), seropositivity among seronegative pre-vaccination (5 studies) or both criteria (1 study)) (Fig. 4). The heterogeneity found in these comparisons was not explained by the predefined factors. The only RCT for this outcome reported $99 \%$ seroconversion for children vaccinated at 8 or 12 months $(n=280)$ (Additional file 6) [70]. Vaccination at 9-11 months versus 12 months yielded similar pooled RR of seroconversion for the 3 subgroup analyses, with an overall RR of 0.93 (95\%CI: 0.90, 0.96; $\mathrm{I}^{2}=61 \%$; 15 studies) (Fig. 5). The two RCT included in this analysis $(n=1401$ and 643) reported similar results: $\mathrm{RR}=0.89(95 \% \mathrm{CI}=0.85,0.93)$ and $\mathrm{RR}=$ $0.92(95 \% \mathrm{CI}=0.87,0.96)$, respectively $[8,69]$. Finally, MCV1 at $\geq 15$ months induced a $3 \%$ higher seroconversion risk compared to 12 months $(\mathrm{RR}=1.03,95 \% \mathrm{CI}$ : $1.00,1.06 ; \mathrm{I}^{2}=35 \% ; 7$ studies), similar to the only RCT ( $n=705)$ [8] (Fig. 6). Evidence from the experimental studies included in the one-dose serological analysis was rated as moderate, based on study design, consistency, low to moderate risk of bias, and dose response [131].

Sensitivity analyses including only studies at low risk of bias found similar results (Additional file 5).

\begin{tabular}{|c|c|c|c|c|c|c|c|c|}
\hline \multirow[b]{2}{*}{ Study or Subgroup } & \multicolumn{2}{|c|}{$<9$ months } & \multicolumn{2}{|c|}{12 months } & \multirow[b]{2}{*}{ Weight } & \multirow{2}{*}{$\begin{array}{l}\text { Risk Ratio } \\
\text { M-H, Random, } 95 \% \mathrm{Cl}\end{array}$} & \multirow{2}{*}{\multicolumn{2}{|c|}{$\begin{array}{l}\text { Risk Ratio } \\
\text { M-H, Random, } 95 \% \mathrm{Cl}\end{array}$}} \\
\hline & Events & Total & Events & Total & & & & \\
\hline \multicolumn{8}{|c|}{ 1.1.1 Seroconversion=fourfold rise } & \\
\hline Stewien 1978 & 5 & 12 & 7 & 7 & $5.2 \%$ & $0.45[0.23,0.87]$ & & \\
\hline Dequadros 1983 & 663 & 940 & 135 & 139 & $44.4 \%$ & $0.73[0.69,0.76]$ & 0 & \\
\hline Gans 1998 & 15 & 23 & 22 & 22 & $17.4 \%$ & $0.66[0.49,0.89]$ & & \\
\hline $\begin{array}{l}\text { Gans } 2004 \\
\text { Subtotal }(95 \% \mathrm{Cl})\end{array}$ & 25 & $\begin{array}{r}29 \\
1004\end{array}$ & 78 & $\begin{array}{r}80 \\
248\end{array}$ & $\begin{array}{r}33.0 \% \\
100.0 \%\end{array}$ & $\begin{array}{l}0.88[0.76,1.03] \\
0.74[0.63,0.87]\end{array}$ & & \\
\hline Total events & 708 & & 242 & & & & & \\
\hline \multicolumn{9}{|c|}{$\begin{array}{l}\text { Heterogeneity: } \mathrm{Tau}^{2}=0.01 ; \mathrm{Chi}^{2}=8.66, \mathrm{df}=3(P=0.03) ; I^{2}=65 \% \\
\text { Test for overall effect: } Z=3.64(P=0.0003)\end{array}$} \\
\hline \multicolumn{9}{|c|}{ 1.1.2 Seroconversion=seropositivity among previously seronegative } \\
\hline Dick 1975 & 16 & 38 & 4 & 5 & $7.0 \%$ & $0.53[0.30,0.94]$ & & \\
\hline Wilkins 1979 & 40 & 78 & 437 & 458 & $24.5 \%$ & $0.54[0.43,0.67]$ & 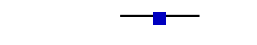 & \\
\hline Halsey 1985 & 90 & 142 & 40 & 40 & $33.4 \%$ & $0.64[0.56,0.73]$ & $\rightarrow$ & \\
\hline Maluf 1985 & 67 & 134 & 7 & 10 & $10.7 \%$ & $0.71[0.46,1.11]$ & & \\
\hline $\begin{array}{l}\text { Gans } 2001 \\
\text { Subtotal }(95 \% \mathrm{Cl})\end{array}$ & 20 & $\begin{array}{r}26 \\
418\end{array}$ & 50 & $\begin{array}{r}52 \\
565\end{array}$ & $\begin{array}{r}24.4 \% \\
100.0 \%\end{array}$ & $\begin{array}{l}0.80[0.64,0.99] \\
0.65[0.55,0.76]\end{array}$ & & \\
\hline Total events & 233 & & 538 & & & & & \\
\hline \multicolumn{9}{|c|}{$\begin{array}{l}\text { Heterogeneity: } \text { Tau }^{2}=0.02 ; \mathrm{Chi}^{2}=8.64, \mathrm{df}=4(P=0.07) ; I^{2}=54 \% \\
\text { Test for overall effect: } Z=5.12(P<0.00001)\end{array}$} \\
\hline \multicolumn{9}{|c|}{ 1.1.3 Seroconversion=fourfold rise or seropositivity among previously seronegative } \\
\hline $\begin{array}{l}\text { He } 2014 \\
\text { Subtotal }(95 \% \mathrm{Cl})\end{array}$ & 138 & $\begin{array}{l}140 \\
140\end{array}$ & 139 & $\begin{array}{l}140 \\
140\end{array}$ & $\begin{array}{l}100.0 \% \\
100.0 \%\end{array}$ & $\begin{array}{l}0.99[0.97,1.02] \\
0.99[0.97,1.02]\end{array}$ & & \\
\hline Total events & 138 & & 139 & & & & & \\
\hline \multirow{2}{*}{\multicolumn{9}{|c|}{$\begin{array}{l}\text { Heterogeneity: Not applicable } \\
\text { Test for overall effect: } Z=0.58(P=0.56)\end{array}$}} \\
\hline & & & & & & & & \\
\hline \multicolumn{7}{|c|}{ Test for subgroup differences: $\mathrm{Chi}^{2}=36.39, \mathrm{df}=2(\mathrm{P}<0.00001), \mathrm{I}^{2}=94.5 \%$} & $\begin{array}{c}1 \\
0.5 \\
\text { Favours [12 months] }\end{array}$ & $1 \frac{1}{1} \quad{ }^{1}$ Favours $[<9$ months $]$ \\
\hline
\end{tabular}




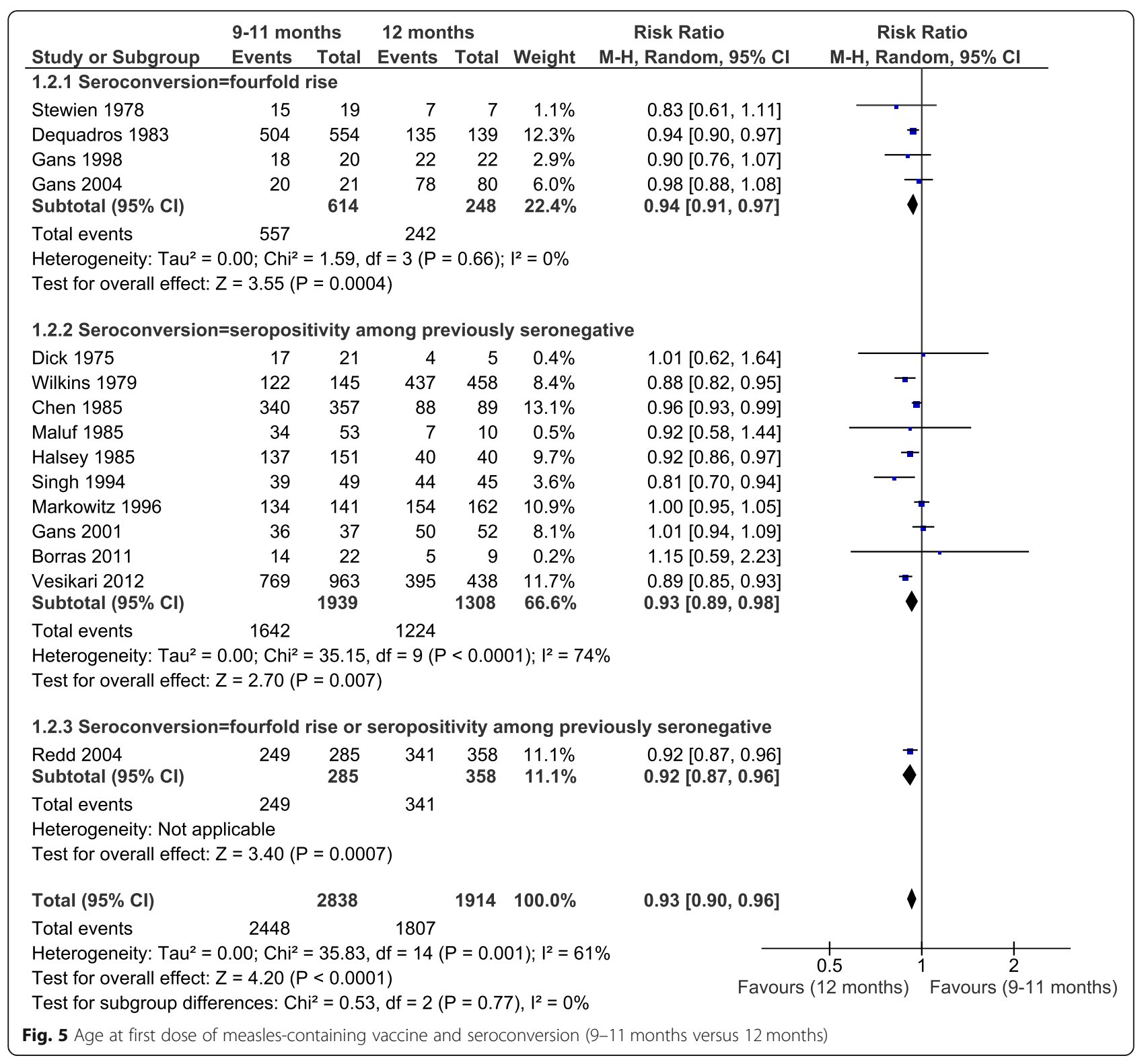

Vaccination at 6 months induced lower seroconversion compared with 9 months ( $\mathrm{RR}=0.74,95 \% \mathrm{CI}$ : 0.68 to 0.82 ; $\mathrm{I}^{2}=65 \% ; 13$ studies). However, there was significant heterogeneity for all sub-analyses, not explained by the predefined effect modifiers (Additional file 7).

Seropositivity after MCV2 was reported in $3 \mathrm{RCT}$ and 4 Non-RCT (Additional file 2). The 3 RCT found high seropositivity in all two-dose recipients. It varied from 95 to $100 \%$ for first dose administered at 4-5, 8, 9, 11 or 12 months $[69,70,74]$. Only Vesikari et al. found a significant difference between MCV1 at 9 (95\%) or 12 months (98\%) [69]. A large non-RCT found increasing seropositivity with older age at MCV1, from $80 \%$ for MCV1 at 7-8 months to $96 \%$ for MCV1 at $10-11$ months $(n=1111)$ [92]. Three
non-RCT showed a similar seropositivity risk for MCV1 at 6 versus 9 months $[6,93]$ or inconsistent results [85] but the number of participants was small (Table 2).

\section{Risk of bias across studies}

Funnel plots did not show much asymmetry but most of the effect estimates were plotted close to the pooled measure, suggesting that publication bias might exist but did not have a major impact on our results (Additional file 8).

\section{Discussion}

Overall, we found robust evidence that increased age at MCV1, from 6 to $\geq 15$ months (by comparing 6 versus 9, 


\begin{tabular}{|c|c|c|c|c|c|c|c|c|}
\hline Study or Subgroup & \multicolumn{2}{|c|}{$\geq 15$ months } & \multicolumn{2}{|c|}{12 months } & Weight & \multirow{2}{*}{$\begin{array}{c}\text { Risk Ratio } \\
\text { M-H, Random, 95\% Cl }\end{array}$} & \multicolumn{2}{|c|}{$\begin{array}{l}\text { Risk Ratio } \\
\text { M-H, Random, } 95 \% \mathrm{Cl}\end{array}$} \\
\hline \multicolumn{8}{|c|}{ 1.4.1 Seroconversion=fourfold rise } & \\
\hline $\begin{array}{l}\text { Kakakios } 1990 \\
\text { Subtotal }(95 \% \mathrm{Cl})\end{array}$ & 53 & $\begin{array}{l}54 \\
54\end{array}$ & 75 & $\begin{array}{l}77 \\
77\end{array}$ & $\begin{array}{l}19.5 \% \\
19.5 \%\end{array}$ & $\begin{array}{l}1.01[0.96,1.06] \\
1.01[0.96,1.06]\end{array}$ & &  \\
\hline \multicolumn{3}{|c|}{$\begin{array}{l}\text { Heterogeneity: Not applicable } \\
\text { Test for overall effect: } Z=0.29(P=0.77)\end{array}$} & 75 & & & & & \\
\hline \multicolumn{9}{|c|}{ 1.4.2 Seroconversion=seropositivity among previously seronegative } \\
\hline Wilkins 1979 & 74 & 78 & 437 & 458 & $18.0 \%$ & $0.99[0.94,1.05]$ & & + \\
\hline Maluf 1985 & 13 & 16 & 7 & 10 & $0.4 \%$ & $1.16[0.73,1.86]$ & & \\
\hline Huang 1990 & 56 & 56 & 92 & 104 & $12.1 \%$ & $1.13[1.04,1.21]$ & & - \\
\hline Singh 1994 & 20 & 21 & 44 & 45 & $7.0 \%$ & $0.97[0.88,1.08]$ & & - \\
\hline $\begin{array}{l}\text { Johnson } 2000 \\
\text { Subtotal }(95 \% \mathrm{Cl})\end{array}$ & 45 & $\begin{array}{r}46 \\
217\end{array}$ & 44 & $\begin{array}{r}47 \\
664\end{array}$ & $\begin{array}{r}9.7 \% \\
47.1 \%\end{array}$ & $\begin{array}{l}1.04[0.96,1.14] \\
1.04[0.98,1.10]\end{array}$ & & - \\
\hline \multicolumn{9}{|c|}{$\begin{array}{l}\text { Heterogeneity: } \mathrm{Tau}^{2}=0.00 ; \mathrm{Chi}^{2}=8.44, \mathrm{df}=4(P=0.08) ; \mathrm{I}^{2}=53 \% \\
\text { Test for overall effect: } Z=1.17(P=0.24)\end{array}$} \\
\hline \multicolumn{9}{|c|}{ 1.4.3 Seroconversion=fourfold rise or seropositivity among previously seronegative } \\
\hline $\begin{array}{l}\text { Redd } 2004 \\
\text { Subtotal }(95 \% \mathrm{Cl})\end{array}$ & 341 & $\begin{array}{l}347 \\
347\end{array}$ & 341 & $\begin{array}{l}358 \\
358\end{array}$ & $\begin{array}{l}33.4 \% \\
33.4 \%\end{array}$ & $\begin{array}{l}1.03[1.00,1.06] \\
1.03[1.00,1.06]\end{array}$ & & 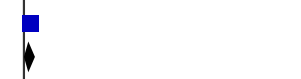 \\
\hline \multicolumn{9}{|c|}{$\begin{array}{l}\text { Heterogeneity: Not applicable } \\
\text { Test for overall effect: } Z=2.26(P=0.02)\end{array}$} \\
\hline Total $(95 \% \mathrm{Cl})$ & & 618 & & 1099 & $100.0 \%$ & $1.03[1.00,1.06]$ & & 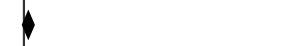 \\
\hline Total events & 602 & & 1040 & & & & & \\
\hline $\begin{array}{l}\text { Heterogeneity: } \mathrm{Tau}^{2}= \\
\text { Test for overall effect } \\
\text { Test for subgroup diff }\end{array}$ & $\begin{array}{l}0.00 ; \mathrm{Chi}^{2} \\
\mathrm{Z}=1.83(\mathrm{~F} \\
\text { rences: } \mathrm{Cl}\end{array}$ & $\begin{array}{l}=9.19, \mathrm{~d} \\
=0.07) \\
\mathrm{i}^{2}=0.72\end{array}$ & $\begin{array}{l}d f=6(P= \\
2, d f=2(F\end{array}$ & $\begin{array}{l}=0.16) ; \\
P=0.70\end{array}$ & $\begin{array}{l}\left.\right|^{2}=35 \% \\
70),\left.\right|^{2}=0 \%\end{array}$ & & $\begin{array}{c}1 \\
0.5 \\
\text { Favours [12 months] }\end{array}$ & ] Favours $[\geq 15$ months $]$ \\
\hline g. 6 Age at first dose $c$ & neasles-c & ntaining & g vaccine a & and se & oconversi & 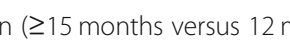 & mins) & \\
\hline
\end{tabular}

9-11 or $<12$ versus $12-14$ and $12-14$ versus $\geq 15$ months), improved antibody response and measles protection among one-dose recipients. Shortly after a second dose, serological studies showed high seropositivity regardless of age at administration of MCV1, with only two trials reporting lower seropositivity for MCV1 given at $\leq 9$ months $[69,92]$. Data from epidemic investigations suggested that less protection with earlier age at MCV1 could persist among two-dose recipients but this is based on only 5 reports, some of which included few cases [10, $38,41]$. In all analyses and for similar age categories, age at MCV1 was more strongly associated with measles risk than with seronegativity risk. This could be partly explained by the more controlled context of the experimental studies but it might also reflect secondary vaccine failures that would not be detected shortly after vaccination [133]. Serological studies have demonstrated that, in infants first vaccinated at 11-12 months, MCV1 induced high seroconversion rates but lower antibody titers than vaccination at 15 months [134]; postsecond dose titers correlated highly with post-MCV1 titers, which may lead to a greater risk of waning immunity over time among poor responders [133-136].
In their systematic review, Uzicanin and Zimmerman reported a median VE of $77.0 \%$ (range: $26-99 \%$ ) and $92.0 \%$ (range: $39-100 \%$ ) after a single dose of MCV1 administered at 9-11 months or $\geq 12$ months, respectively [17]. Lochlainn et al. reviewed immunogenicity, protection and safety for first measles vaccination below the age of 9 months [19]. Both papers summarized studies reporting VE and seroconversion for each age at vaccination. By reviewing studies that compared immunogenicity or VE at different ages at vaccination, we reduced the bias resulting from comparing VE at each age obtained from different studies, where exposition to disease, vaccine ascertainment and other factors could vary. Besides, by examining smaller age categories based on the most common schedule recommendations [14], our review refined the assessment of the role of age at MCV1 with respect to VE, serological results and two-dose protection. When there were few unvaccinated cases, as in school outbreak investigations, VE by age at vaccination could not be estimated or was difficult to interpret. We circumvented this problem by analyzing only vaccinated individuals and calculating their 


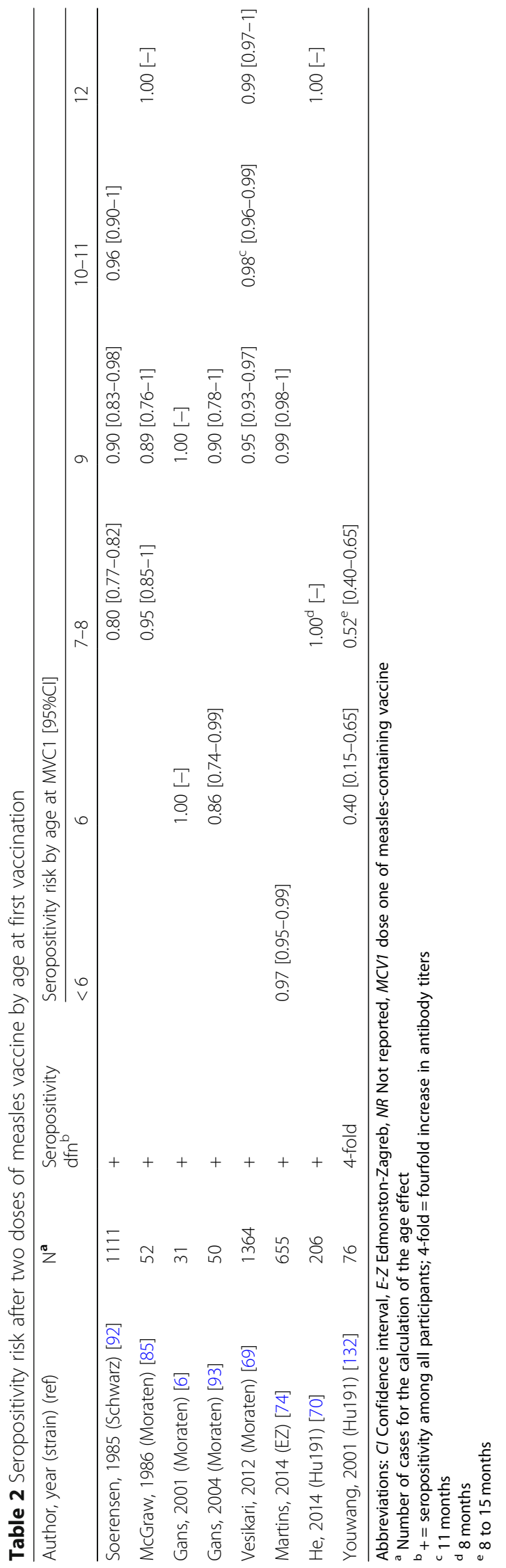


relative risks of measles for different ages at vaccination, thus minimizing the risk of bias associated with VE calculation from epidemics among highly vaccinated populations.

This review was limited by the quality of the epidemiological studies as only $27 \%$ were at low risk of bias. However, it is reassuring that the results of serological studies at low risk of bias were very much in line with those of epidemic investigations. Only $13 \%$ of the serological studies measured neutralizing antibodies, meaning that seroconversion might be underestimated when the protection threshold was quantified by less sensitive assays like HAI and ELISA [26-28, 137]. This would not change our conclusions if low levels of neutralizing antibodies were not protective in the medium term, as suggested by epidemiological results. As expected, data from the eligible studies were heterogeneous. Therefore, we restricted and stratified studies included in the quantitative analyses. We still found heterogeneity in some of the serological subanalyses, which was not explained by region, year, vaccine strain or antibody assay. However, protection and immunogenicity pooled estimates showed the same direction of effect and were coherent, indicating that our results are robust despite the heterogeneity [30]. We could not use 12-month-old as the reference category for measles risk as most of the epidemiological studies presented together children vaccinated at 12 to 14 months. Even if the 12 months category would have been preferred to have data more comparable to immunological studies, vaccination at 12 to 14 months reflects the field reality of countries recommending measles vaccine at 12 months. Using it as a reference group was more informative than pooling the few studies that reported vaccination at 12 months. Finally, data on measles risk and seropositivity among two-dose recipients were limited and summary measures could not be calculated for these outcomes, highlighting the need for further evaluations of the effect of age at first dose after MCV2.

Over the last 20 years, two phenomena have influenced a progressive epidemiological transition with implications for policy concerning age at measles vaccination: first, infants have increasingly been born to vaccinated mothers and received less placental transferred maternal antibodies [138]; second, two-dose schedules became recommended worldwide [14]. Most of the studies included in this review had participants born to mothers with naturally acquired immunity. As no study presented information about maternal status (disease or vaccinated), it was not possible to do a sensitivity analysis on children born to vaccinated mothers who now represent the majority of newborns in countries with high vaccination coverage. However, age-differences in seroconversion among infants without detectable maternal antibodies before vaccination suggest that age-effect will still be present even in the situation of lower maternal antibody transfer [6].

All five WHO regions have set a target for measles elimination [2]. Although huge progress has been made in decreasing measles morbidity and mortality worldwide, only the Americas region has attained and maintained elimination [139]. Elimination requires achieving and maintaining the highest one-dose and two-dose vaccination coverage (95\%) [2] while minimizing primary and secondary failures. Seropositivity data showed that primary vaccine failures are uncommon shortly after two doses even when MCV1 was administered at an age as early as 9 months $[6,69$, $70,74,94]$. However, these serological studies did not provide information about the risk of secondary vaccine failures. Epidemiological data concerning vaccine failures and sero-surveys suggest greater vulnerability than expected from seroconversion rates [12, 140 143]. The high correlation found between first- and second-dose antibody titers [97] and our post-first dose results suggest that age at MCV1 might still play a role in the current two-doses measles epidemiological context. While some researchers had advocated to decrease the age at first dose to 9 months in European countries [144, 145], our review rather supports to maintain the recommendation of MCV1's administration after the first year of life and even consider vaccination at 15 months. In elimination and low-transmission jurisdictions the risk of measles for infants is very low [146] and a change of age at first vaccination would only increase vulnerability during few months (from 12 to 15 months of age for example) among infants of families accepting vaccination. Even considering this temporary increased risk in infants, older age at vaccination might slightly improve overall immunity in each cohort, which may be valuable if $94 \%$ immunity is necessary to maintain elimination and minimize secondary spread following importation [147]. The African and South-East Asian regions accounted for $85 \%$ of measles deaths in 2016 [139]. In these contexts, early vaccination at 9 months may still be warranted to protect infants from severe disease [32], even if the risk of vaccine failures might increase.

While two-dose vaccination coverage is the most critical factor in interrupting measles transmission [148], older age at first vaccination may be necessary to keep population immunity level high enough to maintain elimination. 


\section{Conclusion}

In children born to mothers who had measles, an earlier age at MCV1 decreases measles protection and immunogenicity after one dose and might also decrease protection after two doses of measles vaccine. For children born to vaccinated mothers, the effect of age at MCV1 in two-dose programs warrants further evaluation.

\section{Supplementary information}

Supplementary information accompanies this paper at https://doi.org/10. 1186/s12879-020-4870-x

Additional file 1. Systematic review protocol. This document describes the protocol for the systematic review and meta-analysis.

Additional file 2. Table - Characteristics of included studies. This table describes the characteristics (first author, year, country, number of cases or participants, vaccine strain and study design) of the studies included in the review.

Additional file 3. Figure - Risk of bias of the observational studies. This figure represents the evaluation of the risk of bias (global and for each item) of the observational studies included in the analysis of measles protection.

Additional file 4. Figure - Risk of bias of the experimental studies. This figure represents the evaluation of the risk of bias (global and for each item) of the experimental studies (RCT and non-RCT) included in the immunogenicity analysis.

Additional file 5. Table - Sensitivity analysis with studies at low risk of bias. This table shows the effect estimate for each outcome including only the studies evaluated as having a low risk of bias.

Additional file 6. Table - Seroconversion after one dose of MCV by age at vaccination. This table describes the seroconversion risk by age at vaccination of all studies included in the one-dose immunogenicity analysis.

Additional file 7. Figure - Seroconversion after one dose of MCV: 6 versus 9 months. This figure is a forest plot of the meta-analysis comparing seroconversion after one dose of MCV at 6 months versus 9 months of age.

Additional file 8. Figure - Funnel plots. This figure represents the funnel plots for each outcome.

\section{Abbreviations}

AR: Attack rates; CF: Complement fixation test; Cl: Confidence interval/s; ELISA: Enzyme immunoassay; HAl: Hemagglutination assay; MCV1: First dose of a measles-containing vaccine; MCV2: Second dose of a measles-containing vaccine; OR: Odds ratio; PRN: Plaque reduction neutralization test; RCT: Randomized controlled trial; RR: Risk ratio; VE: Vaccine effectiveness; WHO: World Health Organization

\section{Acknowledgements}

We would like to thank Jacques Brisson and Hervé Tchala Vignon Zomahoun (Laval University) for their comments and insights during the elaboration of the review protocol, as well as Frédéric Bergeron (Laval University) for his help in the development of the search strategy.

\section{Authors' contributions}

GDS and SCP designed the study. SCP and MNB carried out the search, data extraction and data analysis. GDS, SCP and AB reviewed and interpreted the results. SCP prepared the manuscript. All authors read and approved the final manuscript.

\section{Funding}

This research did not receive any specific grant from funding agencies in the public, commercial, or not-for-profit sectors.

\section{Availability of data and materials}

Data sharing is not applicable to this article as no datasets were generated or analysed during the current study. All articles included in this review are publicly available.

\section{Ethics approval and consent to participate}

This study did not require ethical approval because it relied only on publicly available data.

\section{Consent for publication}

Not applicable.

\section{Competing interests}

GDS has received investigator-initiated grants from GSK and Pfizer; has received honorarium for expert testimony from the Ontario Nurse Association, from the Quebec Ministry of Justice and from GSK. SCP, MNB and AB have no conflicts of interest to declare.

\section{Author details}

${ }^{1}$ Department of Social and Preventive Medicine, Laval University, 1050, Avenue de la Médecine, Quebec, QC G1V OA6, Canada. ${ }^{2} \mathrm{CHU}$ de Québec Université Laval Research Center, 2400, Avenue d'Estimauville, Quebec, QC G1E 7G9, Canada. ${ }^{3}$ Institut National de Santé Publique du Québec, 2400, Avenue d'Estimauville, Quebec, QC G1E 7G9, Canada.

Received: 12 April 2018 Accepted: 11 February 2020

Published online: 29 March 2020

References

1. Moss WJ, Griffin DE. Measles. Lancet. 2012;379:153-64.

2. World Health Organization. Global measles and rubella strategic plan. 2012 2020. 2012. http://apps.who.int/iris/bitstream/10665/44855/1/97892415033 96 eng.pdf. Accessed 15 Apr 2014

3. Chawla U, Benera SK, Bandyopadhyay S, Chaudhary BN, Gupta OP, Khallendra RK, Ramaswamy J, Khare S, Sharma RS, Dutta KK. Field evaluation of measles vaccine efficacy in new Seemapuri, Shahdara zone-Delhi during 1990. J Commun Disord. 1990:22:134-9.

4. Rivest P, Bedard L, Arruda H, Trudeau G, Remis RS. Risk factors for measles and vaccine efficacy during an epidemic in Montreal. Can J Public Health. 1995;86:86-90.

5. Murray M, Rasmussen Z. Measles outbreak in a northern Pakistani village: epidemiology and vaccine effectiveness. Am J Epidemiol. 2000;151:811-9.

6. Gans H, Yasukawa L, Rinki M, DeHovitz R, Forghani B, Beeler J, Audet S, Maldonado Y, Arvin AM. Immune responses to measles and mumps vaccination of infants at 6, 9, and 12 months. J Infect Dis. 2001;184:817-26.

7. Klinge J, Lugauer S, Korn K, Heininger U, Stehr K. Comparison of immunogenicity and reactogenicity of a measles, mumps and rubella (MMR) vaccine in German children vaccinated at 9-11, 12-14 or 15-17 months of age. Vaccine. 2000;18:3134-40.

8. Redd SC, King GE, Heath JL, Forghani B, Bellini WJ, Markowitz LE. Comparison of vaccination with measles-mumps-rubella vaccine at 9, 12, and 15 months of age. J Infect Dis. 2004;189:S116-22.

9. Leuridan E, Van Damme P. Passive transmission and persistence of naturally acquired or vaccine-induced maternal antibodies against measles in newborns. Vaccine. 2007:25:6296-304

10. Paunio M, Peltola H, Valle M, Davidkin I, Virtanen M, Heinonen OP. Twice vaccinated recipients are better protected against epidemic measles than are single dose recipients of measles containing vaccine. J Epidemiol Community Health. 1999:53:173-8.

11. Defay F, De Serres G, Skowronski DM, Boulianne N, Ouakki M, Landry M, Brousseau N, Ward BJ. Measles in children vaccinated with 2 doses of MMR. Pediatrics. 2013;132:e1126-33.

12. Poethko-Muller C, Mankertz A. Sero-epidemiology of measles-specific lgG antibodies and predictive factors for low or missing titres in a German population-based cross-sectional study in children and adolescents (KiGGS). Vaccine. 2011:29:7949-59.

13. Strebel PM, Papania MJ, Fiebelkorn AP, Halsey N. Measles vaccine. In: Plotkin SA, Orenstain WA, Offit PA, editors. Vaccines. 6th ed. China: Elsevier Saunders; 2013.

14. World Health Organization. Measles Vaccine: WHO position paper, April 2017 - Recommendations. Vaccine. 2019;37:219-22. 
15. Strikas RA. Advisory committee on immunization practices recommended immunization schedules for persons aged 0 through 18 years--United States, 2015. MMWR Morb Mortal Wkly Rep. 2015;64:93-4.

16. European Centre for Disease Prevention and Control. Vaccine Schedule. 2015. http://vaccine-schedule.ecdc.europa.eu/Pages/Scheduler.aspx. Accessed 5 May 2016.

17. Uzicanin A, Zimmerman L. Field effectiveness of live attenuated measlescontaining vaccines: a review of published literature. J Infect Dis. 2011; 204(Suppl 1):S133-48.

18. Demicheli V, Rivetti A, Debalini MG, Di Pietrantonj C. Vaccines for measles, mumps and rubella in children. Cochrane Database Syst Rev. 2012;2: CD004407-CD.

19. Lochlainn LN, de Gier B, van der Maas NAT, Rots N, Van Binnendijk RS, De Melker HE, Hahné SJM. Measles vaccination below 9 months of age: systematic literature review and meta-analysis of effects and safety. 2017. http://www.who.int/immunization/sage/meetings/2017/october/7_RIVM_ MCV_Under_6months_systematic_review_.pdf. Accessed 10 Sept 2017.

20. Higgins J, Green S. editors. Cochrane Handbook for Systematic Reviews of Interventions. Version 5.1.0. London: The Cochrane Collaboration; 2011.

21. Liberati A, Altman DG, Tetzlaff J, Mulrow C, Gotzsche PC, loannidis JP, Clarke M, Devereaux PJ, Kleijnen J, Moher D. The PRISMA statement for reporting systematic reviews and meta-analyses of studies that evaluate health care interventions: explanation and elaboration. J Clin Epidemiol. 2009;62:e1-34.

22. Waibale P, Bowlin SJ, Mortimer EA, Whalen C. The effect of human immunodeficiency virus-1 infection and stunting on measles immunoglobulin-G levels in children vaccinated against measles in Uganda. Int J Epidemiol. 1999;28:341-6.

23. Moss W, Scott $\mathrm{S}$. The immunological basis for immunization series. Module 7: measles. Update. 2009;2009 http://apps.who.int/iris/bitstream/10665/4403 8/1/9789241597555_eng.pdf. Accessed 20 May 2016.

24. Orenstein WA, Bernier RH, Dondero TJ, Hinman AR, Marks JS, Bart KJ, Sirotkin B. Field evaluation of vaccine efficacy. Bull World Health Organ. 1985;63:1055-68

25. Orenstein WA, Bernier RH, Hinman AR. Assessing vaccine efficacy in the field. Further observations. Epidemiol Rev. 1988;10:212-41.

26. Chen RT, Markowitz LE, Albrecht P, Stewart JA, Mofenson LM, Preblud SR, Orenstein WA. Measles antibody: reevaluation of protective titers. J Infect Dis. 1990;162:1036-42.

27. Neumann PW, Weber JM, Jessamine AG, O'Shaughnessy MV. Comparison of measles antihemolysin test, enzyme-linked immunosorbent assay, and hemagglutination inhibition test with neutralization test for determination of immune status. J Clin Microbiol. 1985;22:296-8.

28. Ratnam S, Gadag V, West R, Burris J, Oates E, Stead F, Bouilianne N. Comparison of commercial enzyme immunoassay kits with plaque reduction neutralization test for detection of measles virus antibody. J Clin Microbiol. 1995;33:811-5

29. NICE. Methods for the development of NICE public health guidance (third edition); 2012. p. 214-186.

30. Higgins JP, Thompson SG, Deeks JJ, Altman DG. Measuring inconsistency in meta-analyses. BMJ. 2003;327:557-60.

31. Mclntyre RC, Preblud SR, Polloi A, Korean M. Measles and measles vaccine efficacy in a remote island population. Bull World Health Organ. 1982;60: 767-75.

32. Aaby P, Bukh J, Leerhoy J, Lisse IM, Mordhorst CH, Pedersen IR. Vaccinated children get milder measles infection: a community study from GuineaBissau. J Infect Dis. 1986;154:858-63.

33. Hull HF, Williams PJ, Oldfield F. Measles mortality and vaccine efficacy in rural West Africa. Lancet. 1983;1:972-5.

34. Anonymus. Measles in Brazil. EPI Newsl. 1984;6:1-3.

35. Nkowane BM, Bart SW, Orenstein WA, Baltier M. Measles outbreak in a vaccinated school population - epidemiology, chains of transmission and the role of vaccine failures. Am J Public Health. 1987;77:434-8.

36. McCombie SC, Worrell RD, Porter BW, Browning JA, Ray CG. Risk for measles related to immunization status in two Tucson high schools. Public Health Rep. 1988;103:162-6.

37. Davis RM, Whitman ED, Orenstein WA, Preblud SR, Markowitz LE, Hinman AR. A persistent outbreak of measles despite appropriate prevention and control measures. Am J Epidemiol. 1987;126:438-49.

38. Robertson SE, Markowitz LE, Berry DA, Dini EF, Orenstein WA. A million dollar measles outbreak: epidemiology, risk factors, and a selective revaccination strategy. Public Health Rep. 1992;107:24-31.
39. George K, Joseph A, Muliyil J, Abraham S, Bhattacharji S, John KR. Measles vaccination before nine months. Tropical Med Int Health. 1998:3:751-6.

40. Sharma RS, Chawla U, Datta KK. Field evaluation of measles vaccine efficacy in Najafgarh zone of Delhi. J Commun Disord. 1988;20:38-43.

41. Hersh BS, Markowitz LE, Hoffman RE, Hoff DR, Doran MJ, Fleishman JC, Preblud SR, Orenstein WA. A measles outbreak at a college with a prematriculation immunization requirement. Am J Public Health. 1991;81: 360-4.

42. Lee MS, King CC, Jean JY, Kao CL, Wang CC, Ho MS, Chen CJ, Lee GC. Seroepidemiology and evaluation of passive surveillance during 1988-1989 measles outbreak in Taiwan. Int J Epidemiol. 1992;21:1165-74.

43. De la Puente ML, Corio R, Alvarez J, Planas C, Isalt R, Marzo M. An epidemic outbreak of measles in a rural area. Aten Primaria. 1993;12:205-6 8-10.

44. Malfait P, Jataou IM, Jollet MC, Margot A, Debenoist AC, Moren A. Measles epidemic in the Urban-Community of Niamey - transmission patterns, vaccine efficacy and immunization strategies, Niger, 1990 to 1991. Pediatr Infect Dis J. 1994:13:38-45.

45. Coetzee N, Hussey GD, Visser G, Barron P, Keen A. The 1992 measles epidemic in Cape Town--a changing epidemiological pattern. S Afr Med J. 1994;84:145-9.

46. McDonnell LF, Jorm LR, Patel MS. Measles outbreak in western Sydney. Vaccine failure or failure to vaccinate? Med J Aust. 1995;162:471-5.

47. Lee MS, Lee LL, Chen HY, Wu YC, Horng CB. Post mass-immunization measles outbreak in Taoyuan County, Taiwan: dynamics of transmission, vaccine effectiveness, and herd immunity. Int J Infect Dis. 1999;3:64-9.

48. Kaninda AV, Legros D, Jataou IM, Malfait P, Maisonneuve M, Paquet C, Moren A. Measles vaccine effectiveness in standard and early immunization strategies, Niger, 1995. Pediatr Infect Dis J. 1998;17:1034-9.

49. Kotb MM, Khella AK, Allam MF. Evaluation of the effectiveness of routine measles vaccination: case-control study. J Egypt Public Health Assoc. 1999; 74:59-68.

50. Hennessey KA, lon-Nedelcu N, Craciun MD, Toma F, Wattigney W, Strebel PM. Measles epidemic in Romania, 1996-1998: assessment of vaccine effectiveness by case-control and cohort studies. Am J Epidemiol. 1999;150: 1250-7.

51. John S, Sanghi S, Prasad S, Bose A, George K. Two doses of measles vaccine: are some states in India ready for it? J Trop Pediatr. 2009;55:253-6.

52. Shelton JD, Jacobson JE, Orenstein WA, Schulz KF, Donnell HD Jr. Measles vaccine efficacy: influence of age at vaccination vs. duration of time since vaccination. Pediatrics. 1978:62:961-4.

53. Judelsohn RG, Fleissner ML, O'Mara DJ. School-based measles outbreaks: correlation of age at immunization with risk of disease. Am J Public Health. 1980;70:1162-5.

54. Faust HS, Thompson FE. Age at and time since vaccination during a measles outbreak in a rural community. Am J Dis Child. 1983;137:977-80.

55. Lopes MH, de Mendonca JS, Pannuti CS, Albrecht P, Biancalana ML, Mantese OC, Correa JF, Amato NV. Measles vaccination: influence of age on its efficacy. Rev Inst Med Trop Sao Paulo. 1989;31:322-7.

56. Wassilak SG, Orenstein WA, Strickland PL, Butler CA, Bart KJ. Continuing measles transmission in students despite school-based outbreak control program. Am J Epidemiol. 1985;122:208-17.

57. Hull HF, Montes JM, Hays PC, Lucero RL. Risk factors for measles vaccine failure among immunized students. Pediatrics. 1985;76:518-23.

58. Chen RT, Goldbaum GM, Wassilak SG, Markowitz LE, Orenstein WA. An explosive point-source measles outbreak in a highly vaccinated population. Modes of transmission and risk factors for disease. Am J Epidemiol. 1989; 129:173-82.

59. Mast EE, Berg JL, Hanrahan LP, Wassell JT, Davis JP. Risk factors for measles in a previously vaccinated population and cost-effectiveness of revaccination strategies. JAMA. 1990;264:2529-33.

60. Hutchins SS, Markowitz LE, Mead P, Mixon D, Sheline J, Greenberg N, Preblud SR, Orenstein WA, Hull HF. A school-based measles outbreak: the effect of a selective revaccination policy and risk factors for vaccine failure. Am J Epidemiol. 1990;132:157-68.

61. Agocs MM, Markowitz LE, Straub I, Domok I. The 1988-1989 measles epidemic in Hungary - assessment of vaccine failure. Int J Epidemiol. 1992; 21:1007-13

62. $\mathrm{Ng} \mathrm{T}$, Hockin J, Stratton F, Allan P. Low measles vaccine failure in a school outbreak--Newfoundland. Can Dis Wkly Rep. 1990;16:53-7.

63. De Serres G, Boulianne N, Meyer F, Ward BJ. Measles vaccine efficacy during an outbreak in a highly vaccinated population: incremental increase in 
protection with age at vaccination up to 18 months. Epidemiol Infect. 1995; 115:315-23.

64. De Serres G, Sciberras J, Naus M, Boulianne N, Duval B, Rochette L. Protection after two doses of measles vaccine is independent of interval between doses. J Infect Dis. 1999;180:187-90.

65. Patel M, Lush D. Measles vaccine effectiveness in central Australian aboriginal children vaccinated at or after eight months of age. Aust N Z J Public Health. 1998;22:729-30.

66. Sutcliffe PA, Rea E. Outbreak of measles in a highly vaccinated secondary school population. CMAJ. 1996;155:1407-13.

67. De Serres G, Boulianne N, Defay F, Brousseau N, Benoit M, Lacoursiere S, Guillemette F, Soto J, Ouakki M, Ward BJ, et al. Higher risk of measles when the first dose of a 2-dose schedule of measles vaccine is given at 12-14 months versus 15 months of age. Clin Infect Dis. 2012;55:394-402.

68. Fowlkes A, Witte D, Beeler J, Audet S, Garcia P, Curns A, Yang C, Fudzulani $\mathrm{R}$, Broadhead R, Bellini WJ, et al. Persistence of vaccine-induced measles antibody beyond age 12 months: a comparison of response to one and two doses of Edmonston-Zagreb measles vaccine among HIV-infected and uninfected children in Malawi. J Infect Dis. 2011;204(Suppl 1):S149-57.

69. Vesikari L, Becker T, Gajdos V, Fiquet A, Thomas S, Richard P, Baudin M. Immunogenicity and safety of a two-dose regimen of a combined measles, mumps, rubella and varicella live vaccine (ProQuad $\left.\left({ }^{\oplus}\right)\right)$ in infants from 9 months of age. Vaccine. 2012;30:3082-9.

70. He H, Chen E, Chen H, Wang Z, Li Q, Yan R, Guo J, Zhou Y, Pan J, Xie S. Similar immunogenicity of measles-mumps-rubella (MMR) vaccine administrated at 8 months versus 12 months age in children. Vaccine. 2014; 32:4001-5.

71. Anonymus. Measles immunity in the first year after birth and the optimum age for vaccination in Kenyan children. Collaborative study by the Ministry of Health of Kenya and the World Health Organization. Bull World Health Organ. 1977:55:21-31.

72. Markowitz LE, Albrecht $P$, Rhodes $P$, Demonteverde $R$, Swint $E$, Maes EF, Powell C, Patriarca PA, Rubenstein B, Dupee R, et al. Changing levels of measles antibody titers in women and children in the United States: impact on response to vaccination. Pediatrics. 1996;97:53-8.

73. Garly ML, Bale C, Martins CL, Monteiro M, George E, Kidd M, Dias F, Aaby P, Whittle HC. Measles antibody responses after early two dose trials in Guinea-Bissau with Edmonston-Zagreb and Schwarz standard-titre measles vaccine: better antibody increase from booster dose of the EdmonstonZagreb vaccine. Vaccine. 2001;19:1951-9.

74. Martins C, Garly ML, Bale C, Rodrigues A, Njie-Jobe J, Benn CS, Whittle H, Aaby $P$. Measles virus antibody responses in children randomly assigned to receive standard-titer Edmonston-Zagreb measles vaccine at 4.5 and 9 months of age, 9 months of age, or 9 and 18 months of age. J Infect Dis. 2014;210:693-700.

75. Ekunwe EO. Separating the factors in measles vaccine failure. Ann Trop Paediatr. 1985;5:103-6.

76. Deivanayagam N, Ramamurthy N, Krishnamurthy PV, Shankar VJ, Ashok TP, Nedunchelian K, Mala N, Ahmed SS. Age for measles immunization seroconversion after measles vaccination at 6-8 months of age--a randomized controlled trial. Indian Pediatr. 1990;27:1171-6.

77. Kaan JA, Vanvlokhoven PCA, Schneeberger PM, Nijhof W. Immunogenicity of measles-vaccine from a hospital based and outreach program in rural Kenya. Trop Dr. 1992;22:30-2.

78. Berry S, Hernandez H, Kanashiro R, Campos M, Azabache V, Gomez G, Gutierrez M, Weirs B, De Quadros C, Halsey N. Comparison of high titer Edmonston-Zagreb, Biken-CAM and Schwarz measles vaccines in Peruvian infants. Pediatr Infect Dis J. 1992;11:822-7.

79. Dick B, Smith T, Kipps A. A minimum age for measles vaccine administration to coloured children. S Afr Med J. 1975:49:1951-4.

80. Guyer B, Atangana S. A programme of multiple-antigen childhood immunization in Yaounde, Cameroon: first-year evaluation, 1975-1976. Bull World Health Organ. 1977;55:633-42.

81. Seghal S, Sharma RS, Das A, Sebastian M, Arora RR. Seroconversion after measles vaccination in infants and children. J Commun Disord. 1983;15:75-9.

82. Halsey NA, Boulos R, Mode F, Andre J, Bowman L, Yaeger RG, Toureau S, Rohde J, Boulos C. Response to measles vaccine in Haitian infants 6 to 12 months old. Influence of maternal antibodies, malnutrition, and concurrent illnesses. N Engl J Med. 1985;313:544-9.

83. Saha SM, Aggarwal RK, Sood DK, Saxena SN. Seroconversion in different age groups after measles vaccination. Indian J Pediatr. 1985;52:303-5.
84. Maluf EM, Ribeiro RC, Rodriguez MA, Skraba I, de Carvalho JF. Induction of specific antibodies by measles vaccine. Study in normal and undernourished infants 6 to 24-months old. Rev Inst Med Trop Sao Paulo. 1985:27:353-60.

85. McGraw TT. Reimmunization following early immunization with measles vaccine: a prospective study. Pediatrics. 1986;77:45-8.

86. Swami SS, Chandra S, Dudani IU. Seroconversion following measles immunisation. J Commun Disord. 1987:19:141-5.

87. Gendrel D, Garin D, Dutailly C, Engohan E, Gendrel C, Moussavou A, Hamono B. Immunization of young infants with high doses of Schwartz measles vaccine. Pediatr Infect Dis J. 1988;7:523-5.

88. Jain DC, Meena HS, Yadav BS, Meena KC, Khare S, Datta KK. Seroepidemiology of measles--a three years prospective study in a rural population of Rajasthan. J Commun Disord. 1990;22:165-72.

89. Job JS, Halsey NA, Boulos R, Holt E, Farrell D, Albrecht P, Brutus JR, Adrien $M$, Andre J, Chan E. Successful immunization of infants at 6 months of age with high dose Edmonston-Zagreb measles vaccine. Cite Soleil/JHU project team. Pediatr Infect Dis J. 1991;10:303-11.

90. Adu FD, Omotade OO, Oyedele Ol, Ikusika O, Odemuyiwa SO, Onoja AL. Field trial of combined yellow fever and measles vaccines among children in Nigeria. East Afr Med J. 1996;73:579-82.

91. Borras E, Urbiztondo L, Costa J, Batalla J, Torner N, Plasencia A, Salleras L, Dominguez A. Working Group for the Study of Measles Immunity in C. Measles antibodies and response to vaccination in children aged less than 14 months: implications for age of vaccination. Epidemiol Infect. 2012;140:1599-606.

92. Soerensen B, Takeda AK, Nakandakare IK, Curi Lde C, Umekita LF, Zuccas WA, Guidoni R, Magalhaes E, Britto SS, Feijo El. Measles: optimum age and number of doses recommended for vaccination in Brazil. Rev Inst Med Trop Sao Paulo. 1985;27:55-65.

93. Gans HA, Yasukawa LL, Alderson A, Rinki M, DeHovitz R, Beeler J, Audet S, Maldonado $Y$, Arvin AM. Humoral and cell-mediated immune responses to an early 2-dose measles vaccination regimen in the United States. J Infect Dis. 2004;190:83-90.

94. Stewien KE, Barbosa V, de Lima OS, Osiro K. The influence of maternally derived antibody on the efficacy of further attenuated measles vaccine. Infection. 1978;6:207-10.

95. Mittal SK, Gulati A, Kumari P, Bala V, Gupta S. Seroconversion following measles immunisation. Indian Pediatr. 1979;16:309-11.

96. Shaoyuan W, Xiuqing X, Yihao Z, Shuwang S, Haijiang L, Jingcai L, Bincheng $H$, Hongye $X$, Tengxiao L. An investigation of the causes of failures in measles vaccination in early infancy. J Biol Stand. 1982;10:197-203.

97. Dequadros CA. Seroconversion rates and measles antibody-titers induced by measles vaccination in Latin-American children 6 to 12 months of age. Rev Infect Dis. 1983;5:596-605.

98. Kakakios AM, Burgess MA, Bransby RD, Quinn AA, Allars HM. Optimal age for measles and mumps vaccination in Australia. Med J Aust. 1990;152:472-4.

99. Rogers S, Sanders RC, Alpers MP. Immunogenicity of standard dose Edmonston-Zagreb measles vaccine in highland Papua new Guinean children from four months of age. J Trop Med Hyg. 1991;94:88-91.

100. Abanamy A, Khalil M, Salman H, Abdel AM. Vaccination of Saudi children against measles with Edmonston-Zagreb. Ann Saudi Med. 1992;12:110-1.

101. Gans HA, Arvin AM, Galinus J, Logan L, DeHovitz R, Maldonado Y. Deficiency of the humoral immune response to measles vaccine in infants immunized at age 6 months. JAMA. 1998;280:527-32.

102. Miller G, Gale J, Villarejos V, James W, Arteaga CG, Casey H, Henderson DA. Edmonston $B$ and a further attenuated measles vaccine--a placebo controlled double blind comparison. Am J Public Health Nations Health. 1967:57:1333-40.

103. Ruben FL, Smith EA, Foster SO, Casey HL, Pifer JM, Wallace RB, Atta Al, Jones WL, Arnold RB, Teller BE, et al. Simultaneous administration of smallpox, measles, yellow fever, and diphtheria-pertussis-tetanus antigens to Nigerian children. Bull World Health Organ. 1973;48:175-81.

104. Wallace RB, Landrigan PJ, Smith EA, Pifer J, Teller B, Foster SO. Trial of a reduced dose of measles vaccine in Nigerian children. Bull World Health Organ. 1976;53:361-4.

105. Wilkins J, Wehrle PF. Additional evidence against measles vaccine administration to infants less than 12 months of age: altered immune response following active/passive immunization. J Pediatr. 1979:94:865-9.

106. Ogunmekan DA, Harry TO. Optimal age for vaccinating Nigerian children against measles. II. Seroconversion to measles vaccine in different age groups. Trop Geogr Med. 1981;33:379-82. 
107. Ogunmekan DA, Bracken P, Marshall WC. An assessment of the effectiveness of the measles immunization programme in Lagos, Nigeria. Ann Trop Med Parasitol. 1981;75:87-92.

108. de Haas PW, Masurel N, Anker WJ. Measles in Tanzania: antibody response in children after vaccination and antibody state of mothers and newborns Trans R Soc Trop Med Hyg. 1983;77:267-70.

109. Climie A, Andre FE. Field trial of a heat-stable measles vaccine in Papua New Guinea. J Trop Med Hyg. 1984;87:249-55.

110. Job JS, John TJ, Joseph A. Antibody response to measles immunization in India. Bull World Health Organ. 1984;62:737-41.

111. Chen ST, Lam SK. Optimum age for measles immunization in Malaysia. Med J Malaysia. 1985:40:281-8.

112. Lhuillier M, Mazzariol MJ, Zadi S, Cam N, Bentejac MC, Adamowicz L, Marie FN, Fritzell B. Study of combined vaccination against yellow fever and measles in infants from six to nine months. J Biol Stand. 1989;17:9-15.

113. Tidjani O, Grunitsky B, Guérin N, Lévy-Bruhl D, Lecam N, Xuereff C, Tatagan K. Serological effects of Edmonston-Zagreb, Schwarz, and AIK-C measles vaccine strains given at ages 4-5 or 8-10 months. Lancet. 1989;2:1357-60.

114. Huang LM, Lee CY, Hsu CY, Huang SS, Kao CL, Wu FF, Lee CC, Chang HS, Huang LY. Effect of monovalent measles and trivalent measles-mumpsrubella vaccines at various ages and concurrent administration with hepatitis B vaccine. Pediatr Infect Dis J. 1990;9:461-5.

115. Makino S, Sasaki K, Nakayama T, Oka S, Urano T, Kimura M, Kawana R, Yamamura AM. A new combined trivalent live measles (AlK-C strain), mumps (Hoshino strain), and rubella (Takahashi strain) vaccine. Findings in clinical and laboratory studies. Am J Dis Child. 1990;144:905-10.

116. Kiepiela P, Coovadia HM, Loening WEK, Coward P, Botha G, Hugo J, Becker PJ. Lack of efficacy of the standard potency Edmonston-Zagreb live, attenuated measles-vaccine in African infants. Bull World Health Organ. 1991;69:221-7.

117. Soula G, Sylla A, Pichard E, Kodio B, Bentejac MC, Teulieres L, Saliou P. A new combined vaccine against yellow fever and measles in infants aged 6 to 24 months in Mali. Bull Soc Pathol Exot. 1991;84:885-97.

118. Giammanco G, Livolti S, Salemi I, Bilancia GG, Mauro L. Immune-response to simultaneous Administration of a Combined Measles, mumps and rubella vaccine with booster doses of diphtheria-tetanus and poliovirus vaccine. Eur J Epidemiol. 1993;9:199-202.

119. Johnson CE, Nalin DR, Chui LW, Whitwell J, Marusyk RG, Kumar ML. Measles vaccine immunogenicity in 6- versus 15 -month-old infants born to mothers in the measles vaccine era. Pediatrics. 1994;93:939-44.

120. Singh R, John TJ, Cherian T, Raghupathy P. Immune response to measles, mumps and rubella vaccine at 9, 12 and 15 months of age. Indian J Med Res. 1994;100:155-9.

121. Kumar ML, Johnson CE, Chui LW, Whitwell JK, Staehle B, Nalin D. Immune response to measles vaccine in 6-month-old infants of measles seronegative mothers. Vaccine. 1998;16:2047-51.

122. Johnson CE, Darbari A, Darbari DS, Nalin D, Whitwell J, Chui LW, Cleves MA, Kumar ML. Measles vaccine immunogenicity and antibody persistence in 12 vs 15-month old infants. Vaccine. 2000;18:2411-5.

123. Diaz-Ortega JL, Zarate-Aquino ML, Valdespino-Gomez JL, Cardenas-Ayala VM, Ruiz-Matus C. Seroconversion with measles vaccine in children 8-18 months old. Bol Med Hosp Infant Mex. 1986;43:526-31.

124. Markowitz LE, Sepulveda J, Diaz-Ortega JL, Valdespino JL, Albrecht P, Zell ER, Stewart J, Zarate ML, Bernier RH. Immunization of six-month-old infants with different doses of Edmonston-Zagreb and Schwarz measles vaccines. N Engl J Med. 1990;322:580-7.

125. Bolotovski VM, Grabowsky M, Clements CJ, Albrecht P, Brenner ER, Zargaryantzs Al, Litvinov SK, Mikheyeva IV. Immunization of 6 and 9 month old infants with AlK-C, Edmonston-Zagreb, Leningrad-16 and Schwarz strains of measles vaccine. Int J Epidemiol. 1994;23:1069-77.

126. Ndumbe PM, Gilchrist SA, Pabst H, Sama MT, Mbede J. Comparison of Edmonston-Zagreb, Connaught and Schwarz measles vaccines in Cameroonian infants aged 3-8 months. Vaccine. 1995;13:276-80.

127. Hussey GD, Goddard EA, Hughes J, Ryon JJ, Kerran M, Carelse E, Strebel PM, Markowitz LE, Moodie J, Barron P, et al. The effect of Edmonston-Zagreb and Schwarz measles vaccines on immune responses in infants. J Infect Dis. 1996;173:1320-6.

128. Lee $\mathrm{YL}$, Black FL, Chen $\mathrm{CL}$, Wu CL, Berman LL. The optimal age for vaccination against measles in an Asiatic city, Taipei, Taiwan: reduction of vaccine induced titre by residual transplacental antibody. Int J Epidemiol. $1983 ; 12: 340-3$
129. Sakatoku H, Nakano T, Arai S, Afari EA. Antibody response to measles immunization in rural Ghanaian infants. J Trop Pediatr. 1994;40:291-3.

130. Zanetta RAC, Amaku M, Azevedo RS, Zanetta DMT, Burattini MN, Massad E. Optimal age for vaccination against measles in the state of São Paulo, Brazil, taking into account the mother's serostatus. Vaccine. 2001;20:226-34.

131. Balshem H, Helfand M, Schunemann HJ, Oxman AD, Kunz R, Brozek J, Vist GE, Falck-Ytter Y, Meerpohl J, Norris S, et al. GRADE guidelines: 3. Rating the quality of evidence. J Clin Epidemiol. 2011;64:401-6.

132. Youwang Y, Ping W, Feng C. Serological and epidemiological effects and influence factors of primary immunization with current live attenuated measles vaccine (Hu191) among infants aged 6-15 months. Vaccine. 2001; 19:1998-2005.

133. Markowitz LE, Albrecht P, Orenstein WA, Lett SM, Pugliese TJ, Farrell D. Persistence of measles antibody after revaccination. J Infect Dis. 1992;166: 205-8.

134. Carazo Perez S, De Serres G, Bureau A, Skowronski DM. Reduced antibody response to infant measles vaccination: effects based on type and timing of the first vaccine dose persist after the second dose. Clin Infect Dis. 2017;65: 1094-102.

135. Stetler HC, Orenstein WA, Bernier RH, Herrmann KL. Impact of revaccinating children who initially received measles vaccine before 10 months of age. Pediatrics. 1986:77:471-6.

136. Davidkin I, Valle M. Vaccine-induced measles virus antibodies after two doses of combined measles, mumps and rubella vaccine: a 12-year followup in two cohorts. Vaccine. 1998;16:2052-7.

137. Miyamura K, Sato TA, Sakae K, Kato N, Ogino T, Yashima T, Sasagawa A, Chikahira M, Itagaki A, Katsuki K, et al. Comparison of gelatin particle agglutination and hemagglutination inhibition tests for measles seroepidemiology studies. Arch Virol. 1997;142:1963-70.

138. Leuridan E, Hens N, Hutse V, leven M, Aerts M, Van Damme P. Early waning of maternal measles antibodies in era of measles elimination: longitudinal study. BMJ. 2010;340:C1626.

139. Dabbagh A, Patel MK, Dumolard L, Gacic-Dobo M, Mulders MN, Okwo-Bele JM, Kretsinger K, Papania MJ, Rota PA, Goodson JL. Progress toward regiona measles elimination - worldwide, 2000-2016. MMWR Morb Mortal Wkly Rep. 2017;66:1148-53.

140. De Serres G, Markowski F, Toth E, Landry M, Auger D, Mercier M, Belanger P, Turmel B, Arruda H, Boulianne N, et al. Largest measles epidemic in North America in a decade--Quebec, Canada, 2011: contribution of susceptibility, serendipity, and superspreading events. J Infect Dis. 2013;207:990-8.

141. Vivancos R, Keenan A, Farmer S, Atkinson J, Coffey E, Dardamissis E, Dillon J, Drew RJ, Fallon M, Huyton R, et al. An ongoing large outbreak of measles in Merseyside, England, January to June 2012. Euro Surveill. 2012;17(19).

142. Antona D, Levy-Bruhl D, Baudon C, Freymuth F, Lamy M, Maine C, Floret D. Parent du Chatelet I. measles elimination efforts and 2008-2011 outbreak, France. Emerg Infect Dis. 2013;19:357-64.

143. Muscat M, Marinova L, Mankertz A, Gatcheva N, Mihneva Z, Santibanez S, Kunchev A, Filipova R, Kojouharova M. The measles outbreak in Bulgaria, 2009-2011: an epidemiological assessment and lessons learnt. Euro Surveill. 2016;21:30152.

144. Gagneur A, Pinquier D, Aubert M, Balu L, Brissaud O, De Pontual L, Le Guen CG, Hau-Rainsard I, Mory O, Picherot G, et al. Kinetics of decline of maternal measles virus-neutralizing antibodies in sera of infants in France in 2006. Clin Vaccine Immunol. 2008;15:1845-50.

145. Leuridan E, Sabbe M, Van Damme P. Measles outbreak in Europe: susceptibility of infants too young to be immunized. Vaccine. 2012;30:5905-13.

146. Fiebelkorn AP, Redd SB, Gastanaduy PA, Clemmons N, Rota PA, Rota JS, Bellini WJ, Wallace GS. A comparison of Postelimination measles epidemiology in the United States, 2009-2014 versus 2001-2008. J Pediatric Infect Dis Soc. 2017;6:40-8.

147. Gay NJ. The theory of measles elimination: implications for the design of elimination strategies. J Infect Dis. 2004;189(Suppl 1):S27-35.

148. Castillo-Solorzano C, Marsigli C, Danovaro-Holliday MC, Ruiz-Matus C, Tambini G, Andrus JK. Measles and rubella elimination initiatives in the Americas: lessons learned and best practices. J Infect Dis. 2011;204(Suppl 1): S279-83.

\section{Publisher's Note}

Springer Nature remains neutral with regard to jurisdictional claims in published maps and institutional affiliations. 